\title{
1 Constitution, oxidation and creep of 2 eutectic and eutectoid Mo-Si-Ti alloys
}

Daniel Schliephake ${ }^{1}$, Alexander Kauffmann $n^{1,}{ }^{*}$, Xiangna Cong ${ }^{1}$, Camelia

Gombola1, Maria Azim², Bronislava Gorr², Hans-Jürgen Christ², and Martin Heilmaier $^{1}$

\section{${ }^{1}$ Karlsruhe Institute of Technology (KIT), Institute for Applied}

\section{Materials (IAM-WK), Germany}

\section{University of Siegen, Germany}

* Corresponding author: Alexander Kauffmann; alexander.kauffmann@kit.edu

\section{Abstract}

In the present contribution, we describe the successful development of two ternary Mo-Si-Ti alloys with two-phase eutectic and eutectoid microstructure, respectively. In the case of Mo-20.0Si-52.8Ti (at.\%), a fully eutectic microstructure consisting of body-centered cubic (bcc) solid solution (Mo,Ti, $\mathrm{Si})$ and hexagonal $(\mathrm{Ti}, \mathrm{Mo})_{5} \mathrm{Si}_{3}$ can be obtained in very good agreement with thermodynamic calculations. A fully eutectoid decomposed microstructure is observed subsequent to heat-treatment at $1300{ }^{\circ} \mathrm{C}$ for $200 \mathrm{~h}$ in the case of Mo-21Si-34Ti (at.\%). For this alloy, bcc (Mo,Ti,Si) and tetragonal $(\mathrm{Mo}, \mathrm{Ti})_{5} \mathrm{Si}_{3}$ appears after decomposition from the A15-type (Mo,Ti) $)_{3} \mathrm{Si}$. Besides that, a small amount of hexagonal (Ti,Mo) ${ }_{5} \mathrm{Si}_{3}$ forms in the silicide lamellae, too, which is attributed to Ti segregations in the as-cast microstructure. In addition to the focus on microstructure, both oxidation and creep behavior were preliminarily investigated and compared to other state-of-the-art Mo-based alloys. In the case of the eutectic alloy, a promising and unexpected oxidation resistance at $800{ }^{\circ} \mathrm{C}$ is observed whereas the eutectoid alloy exhibits catastrophic oxidation; a behavior that is typically observed under these conditions in alloys containing Mo-rich solid solution. The eutectic alloy shows an approximately one order of magnitude higher creep rate within the investigated temperature and stress 
range as compared to the eutectoid decomposed counterpart. This is attributed to the rather low intrinsic creep resistance of the hexagonal $(\mathrm{Ti}, \mathrm{Mo})_{5} \mathrm{Si}_{3}$ and generally lower melting point of the former alloy, whereas in the latter case, creep seems to be controlled by the deformation of the bcc solid solution $(\mathrm{Mo}, \mathrm{Ti}, \mathrm{Si})$ and the tetragonal $(\mathrm{Mo}, \mathrm{Ti})_{5} \mathrm{Si}_{3}$.

Keywords: A. silicides, B. creep, B. oxidation, B. phase transformation, C. casting

\section{Introduction}

Refractory metal-silicide alloys are of interest for structural applications at elevated temperatures since they possess high melting points close to or above $2000{ }^{\circ} \mathrm{C}$ and, thus, may show prospect for good creep and oxidation resistance at temperatures up to $1200^{\circ} \mathrm{C}$. During the last two decades, it turned out that some $\mathrm{Nb}$ - and Mo-silicides are promising candidates from this group of materials meeting the requirements for structural applications in aerospace engines and gas turbines for power generation [1, 2, 3, 4, 5]. However, $\mathrm{Nb}$-silicides particularly suffer from poor oxidation resistance [3], while Mo-Si-B alloys consisting of Mo-rich bcc solid solution, tetragonal $\mathrm{Mo}_{5} \mathrm{SiB}_{2}$ and $\mathrm{A} 15$-type $\mathrm{Mo}_{3} \mathrm{Si}$ are intrinsically brittle at room temperature [6] and exhibit a rather high density of about $9.5 \mathrm{~g} / \mathrm{cm}^{3}$ [7] compared to Ni-base superalloys with $8.2-9 \mathrm{~g} / \mathrm{cm}^{3}$ [8]. Recently, it was found that a certain amount of Ti can stabilize $\mathrm{Mo}_{5} \mathrm{Si}_{3}$ instead of $\mathrm{Mo}_{3} \mathrm{Si}$ beside Mo solid solution and $\mathrm{Mo}_{5} \mathrm{SiB}_{2}$ under thermodynamic equilibrium conditions. In addition, the density of such alloys is significantly reduced by the Ti addition, e.g. $7.8 \mathrm{~g} / \mathrm{cm}^{3}$ for Mo-12.5Si-8.5B-27.5Ti [9]. However, the oxidation resistance of Mo-Si-B$\mathrm{Ti}$ alloys is decreased in the temperature range of 820 to $1200{ }^{\circ} \mathrm{C}$ by the formation of a $\mathrm{SiO}_{2} / \mathrm{TiO}_{2}$ duplex oxide scale, although the oxidation resistance of monolithic $\mathrm{Mo}_{5} \mathrm{Si}_{3}$ alloyed with 40 at.\% $\mathrm{Ti}$ is very good in the whole temperature range [9]. The reason for that is twofold: (i) In the case of the monolithic Ti-containing $\mathrm{Mo}_{5} \mathrm{Si}_{3}, \mathrm{SiO}_{2}$ forms a continuous matrix with dispersed rutile particles while $\mathrm{TiO}_{2}$ becomes the matrix in the case of multiphase Mo-Si-B-Ti alloys. (ii) Multiphase alloys produced by arc-melting and subsequent heat treatments for homogenization in general exhibit rather coarse microstructures. It is well known that the microstructural size scale is important for the oxidation resistance of multiphase Mo-Si-B alloys, since covering the non-oxidation resistant Mo solid solution 
by a protective borosilica scale $[10,11]$ is the crucial step - increasing microstructural dimension generally deteriorates the oxidation resistance [12].

One approach to improve the oxidation resistance could be to reduce the lateral dimensions of the phases by a powder metallurgy processing route including mechanical alloying - however, on the expense of largely increased processing effort [13]. Another approach is to utilize a eutectic reaction or eutectoid decomposition to obtain fine, lamellar microstructures [14]. Like in the case of TiAlbased alloys [15], some investigations on ternary eutectic Mo-Si-B alloys yield both, improved creep resistance and better oxidation resistance $[15,16]$. However, the improvement of creep resistance may also be attributed to the relatively high amount of intermetallic phases present in these ternary alloys, which may likewise be beneficial for the oxidation resistance, too. Nevertheless, even with such a high volume fraction of intermetallic phases, these alloys possess densities greater than $9 \mathrm{~g} / \mathrm{cm}^{3}$. Besides the already mentioned benefit in density, there are at least two known prospects to obtain fine microstructures by a eutectic or eutectoid reaction within the Mo-Si-Ti system as shown by Yang et al. [17]. On the Ti-rich side of the ternary system, there exists a trough with bcc (Mo,Ti,Si) and hexagonal ( $\mathrm{Ti}, \mathrm{Mo})_{5} \mathrm{Si}_{3}$ solidifying by an eutectic reaction. On the Mo-rich side, A15-type (Mo,Ti) ${ }_{3} \mathrm{Si}$ can be obtained in almost monolithic condition from the liquid by congruent solidification. This phase will subsequently decompose into bcc (Mo,Ti,Si) and tetragonal $(\mathrm{Mo}, \mathrm{Ti})_{5} \mathrm{Si}_{3}$ by a eutectoid reaction. Although this approach to obtain fine microstructures in Mo-Si-Ti alloys is known for over 15 years, no efforts were made to investigate the high temperature behavior of these two-phase alloys in greater detail. Therefore, the present work focuses on the preparation of two-phase eutectic and eutectoid alloys in the Mo-Si-Ti system on the basis of thermodynamic calculations as well as their oxidation and creep resistance in the temperature range of 800 to $1300{ }^{\circ} \mathrm{C}$. Furthermore, the benefit of finescaled microstructures for oxidation and, thus, less need for low-viscosity borosilicate scales which is typically achieved by B addition is stressed.

\section{Experimental}

The Calphad software package Pandat (version 2016) with the proprietary database PanMo (version 2016) was used to evaluate suitable alloy compositions [18]. The calculations were performed 
for thermodynamic equilibrium by means of the PanEngine in conjunction with the aforementioned database.

Mo-Si-Ti alloys were prepared from elemental materials by means of arc-melting (AM/0.5 provided by Edmund Bühler $\mathrm{GmbH}$ ). The Ar base pressure for arc-melting was $60 \mathrm{kPa}$ following several alternating iterations of pumping and Ar flooding. Re-melting a $\mathrm{Zr}$ lump in the vacuum chamber prior to every melting step was used in order to reduce residual O. The prepared buttons were flipped and re-melted for at least five times for homogenization. Heat treatments subsequent to casting for eutectoid decomposition were performed under Ar atmosphere in a Gero HTRH 70-600/18 resistance tube furnace.

The density of the alloys was determined using the Archimedes principle utilizing a precision balance (Mettler AE 240). X-ray diffraction (XRD) analyzes in Bragg-Brentano geometry were carried out on a D2 Phaser system by Bruker equipped with a LynxEye line detector. The Cu tube was operated at $30 \mathrm{kV}$ and $10 \mathrm{~mA}$, and the according radiation was filtered by means of a Ni foil. Precise lattice parameters were determined using extrapolation of the peak positions utilizing a Nelson-Riley approach [19]. For hexagonal and tetragonal crystal structures, an adopted least square fitting according to Ref. [20] was used. Scanning electron microscopy (SEM) investigations were performed on a EVO50 (provided by Carl Zeiss AG) system operated at $20 \mathrm{kV}$ equipped with a Thermo Fisher Scientific energy-dispersive X-ray spectroscopy (EDX) system. Electron backscatter diffraction (EBSD) was conducted on an Auriga cross-beam SEM (provided by Carl Zeiss AG) operated at $20 \mathrm{kV}$ using an EDAX DigiView camera (provided by AMETEK GmbH).

The oxidation behavior between 800,1100 and $1200^{\circ} \mathrm{C}$ was studied under both, isothermal and thermal cycling conditions by measuring the weight change with respect to their initial weight of samples with dimensions of $(2 \cdot 2 \cdot 3)$ and $(3 \cdot 3 \cdot 5) \mathrm{mm}^{3}$. The isothermal oxidation behavior was studied by thermogravimetric analysis (TGA) in synthetic air $\left(20.5 \pm 0.5 \mathrm{O}_{2}, \mathrm{~N}_{2}\right.$ balanced) using a Netzsch STA449 F1 Jupiter instrument. The flow rate of the synthetic air was $30 \mathrm{ml} / \mathrm{min}$. For the thermal cycling oxidation experiments, a box-type furnace was used with an exposure time of $1 \mathrm{~h}$ for the first $20 \mathrm{~h}$ of oxidation in laboratory air and alumina crucibles followed by $5 \mathrm{~h}$ and $10 \mathrm{~h}$ cycles. In 
between these individual oxidation periods, the weight of the samples was measured outside the

106 furnace at room temperature using a Sartorius USP 34 C41 balance. Both, isothermal and thermal 107 cycling experiments were performed up to $100 \mathrm{~h}$.

108 To determine the creep behavior, compression creep tests were carried out on a Zwick universal 109 testing device equipped with a Maytec vacuum furnace $\left(<10^{-4} \mathrm{~Pa}\right)$ at temperatures between 1100 and $1101300{ }^{\circ} \mathrm{C}$ on $(3 \cdot 3 \cdot 4.5) \mathrm{mm}^{3}$ samples. Constant true stress was applied for all creep tests by 111 continuously monitoring the creep strain. The punches were made of $\mathrm{SiC}$ and hexagonal BN was used

112 for lubrication. Engineering creep strain was converted into true strain assuming constant sample 113 volume and fed back into the PC controlled loop accounting for the continuously increasing cross114 sectional area of the plastically deforming compressive sample.

\section{3. Results}

\section{Alloy development}

\section{Eutectic alloy}

118 In order to obtain two-phase Mo-Si-Ti alloys, two distinct reactions were systematically investigated,

119 Fig. 1: (i) the eutectic reaction of $\mathrm{L} \rightarrow(\mathrm{Mo}, \mathrm{Ti}, \mathrm{Si})+(\mathrm{Ti}, \mathrm{Mo})_{5} \mathrm{Si}_{3}(\mathrm{~L}$ designates the liquid phase) as well 120 as (ii) the eutectoid decomposition of $(\mathrm{Mo}, \mathrm{Ti})_{3} \mathrm{Si} \rightarrow(\mathrm{Mo}, \mathrm{Ti}, \mathrm{Si})+(\mathrm{Mo}, \mathrm{Ti})_{5} \mathrm{Si}_{3}$.

121 The validity of Calphad simulations (utilizing Pandat software in the present case [18]) for alloy 122 design in the vicinity of the eutectic trough shown in the lower left part of the liquidus projection in 123 Fig. 1 was assessed using several alloys with primary solidifying (i) bcc solid solution (Mo,Ti,Si) or 124 (ii) hexagonal (Ti,Mo) ${ }_{5} \mathrm{Si}_{3}$. The chosen alloy compositions $x_{i}$ are summarized in Table 1. Alloys E1 to 


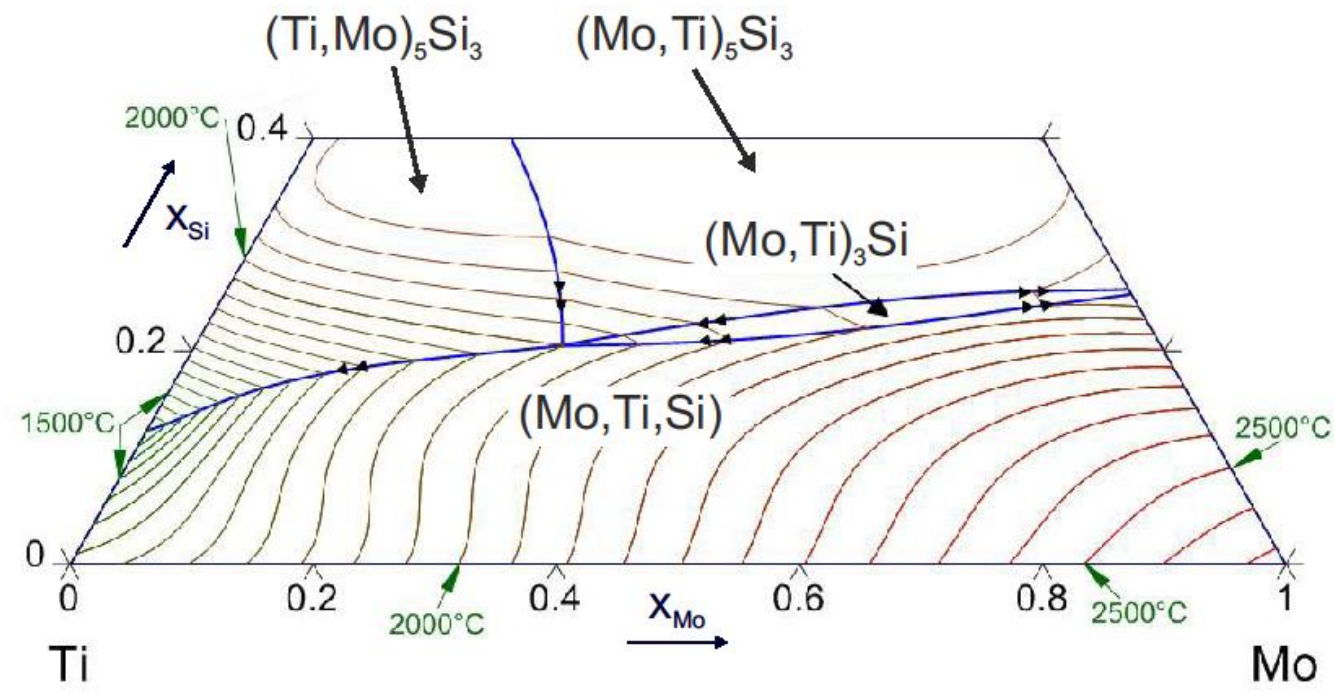

Figure 1: Liquidus projection obtained using Calphad simulations based on the data from Yang et al. [16].

Table 1: Overview on compositions $x_{i}$ and phase fractions $X$ (atomic) and $V$ (volumetric) according to thermodynamic calculations for the alloys E1 to E5. Composition of the primary solidifying phase does not change significantly during primary solidification and the values presented in this table correspond to the composition at the temperature when eutectic solidification starts. The composition for density estimation in the eutectic was obtained at the solidus temperature.

\begin{tabular}{|c|c|c|c|c|c|c|c|c|c|c|c|}
\hline$\#$ & $i$ & $\begin{array}{c}x_{i} / \\
\text { at. } \%\end{array}$ & $\begin{array}{c}\text { primary } \\
\text { phase }\end{array}$ & $\begin{array}{c}x_{i}^{\text {primary }} / \\
\text { at. } \%\end{array}$ & $\begin{array}{c}x_{i}^{\text {liquid }} / \\
\text { at. } \%\end{array}$ & $\begin{array}{c}X^{\text {primary }} / \\
\text { at. } \%\end{array}$ & $\begin{array}{c}X^{\text {liquid } /} \\
\text { at. } \%\end{array}$ & $\begin{array}{c}V^{\text {primary }} / \\
\text { vol. } \%\end{array}$ & $\begin{array}{l}V^{\text {liquid } /} \\
\text { vol.\% }\end{array}$ & $\begin{array}{c}\rho^{\text {primary }} / \\
\mathbf{k g} / \mathbf{m}^{3}\end{array}$ & $\begin{array}{c}\rho^{\text {eutectic/ }} \\
\mathbf{k g} / \mathbf{m}^{3}\end{array}$ \\
\hline \multirow{3}{*}{ E1 } & Mo & 32.6 & \multirow{3}{*}{$(\mathrm{Mo}, \mathrm{Ti}, \mathrm{Si})$} & 67.4 & 28.8 & \multirow{3}{*}{10.0} & \multirow{3}{*}{90.0} & \multirow{3}{*}{10.5} & \multirow{3}{*}{89.5} & \multirow{3}{*}{8355} & \multirow{3}{*}{6238} \\
\hline & $\mathrm{Si}$ & 18.7 & & 3.6 & 20.3 & & & & & & \\
\hline & $\mathrm{Ti}$ & 48.7 & & 29.0 & 50.8 & & & & & & \\
\hline \multirow{3}{*}{ E2 } & Mo & 26.4 & \multirow{3}{*}{ (Mo,Ti,Si) } & 63.2 & 24.6 & \multirow{3}{*}{4.6} & \multirow{3}{*}{95.4} & \multirow{3}{*}{4.7} & \multirow{3}{*}{95.3} & \multirow{3}{*}{8053} & \multirow{3}{*}{5970} \\
\hline & $\mathrm{Si}$ & 19.1 & & 3.8 & 19.8 & & & & & & \\
\hline & $\mathrm{Ti}$ & 54.5 & & 33.0 & 55.5 & & & & & & \\
\hline \multirow{3}{*}{$\mathbf{E 3}$} & Mo & 30.1 & \multirow{3}{*}{ (Mo,Ti,Si) } & 65.3 & 27.4 & \multirow{3}{*}{7.1} & \multirow{3}{*}{92.9} & \multirow{3}{*}{7.4} & \multirow{3}{*}{92.6} & \multirow{3}{*}{8232} & \multirow{3}{*}{6151} \\
\hline & $\mathrm{Si}$ & 19.0 & & 4.0 & 20.2 & & & & & & \\
\hline & $\mathrm{Ti}$ & 50.9 & & 30.7 & 52.5 & & & & & & \\
\hline \multirow{3}{*}{ E4 } & Mo & 25.4 & \multirow{3}{*}{$(\mathrm{Ti}, \mathrm{Mo})_{5} \mathrm{Si}_{3}$} & 13.2 & 27.9 & \multirow{3}{*}{16.7} & \multirow{3}{*}{83.3} & \multirow{3}{*}{16.0} & \multirow{3}{*}{84.0} & \multirow{3}{*}{5088} & \multirow{3}{*}{6159} \\
\hline & $\mathrm{Si}$ & 23.1 & & 37.5 & 20.2 & & & & & & \\
\hline & $\mathrm{Ti}$ & 51.5 & & 49.3 & 51.9 & & & & & & \\
\hline \multirow{3}{*}{ E5 } & Mo & 27.2 & \multirow{3}{*}{-} & \multirow{3}{*}{-} & & & & & & & \\
\hline & $\mathrm{Si}$ & 20.0 & & & - & - & - & - & - & - & 6251 \\
\hline & $\mathrm{Ti}$ & 52.8 & & & & & & & & & \\
\hline
\end{tabular}

126 Solidification is simulated under equilibrium conditions using the Pandat software package. The

127 composition and volume fraction of the primary phase at the temperature when the eutectic reaction

128 starts, are presented in Fig. 2 and compared to experimental values determined by SEM-EDX and

129 SEM image analyses. The conversion of atomic phase fraction as provided by the Pandat software into

130 volumetric phase fraction was based on the crystallographic density of the contributing phases. For 
131 this purpose, the compositions of the phases suggested by the simulation as well as the dimensions of 132 the respective unit cells of bcc (Mo,Ti,Si) and hexagonal ( $\mathrm{Ti}, \mathrm{Mo})_{5} \mathrm{Si}_{3}$ obtained by XRD measurements 133 were used. For all four alloys E1 to E4 a very good agreement between the equilibrium calculation and experimental results is observed with respect to both, chemical composition as well as volume fraction. Especially, the Si content in the respective phases is very well reproduced by the simulation.

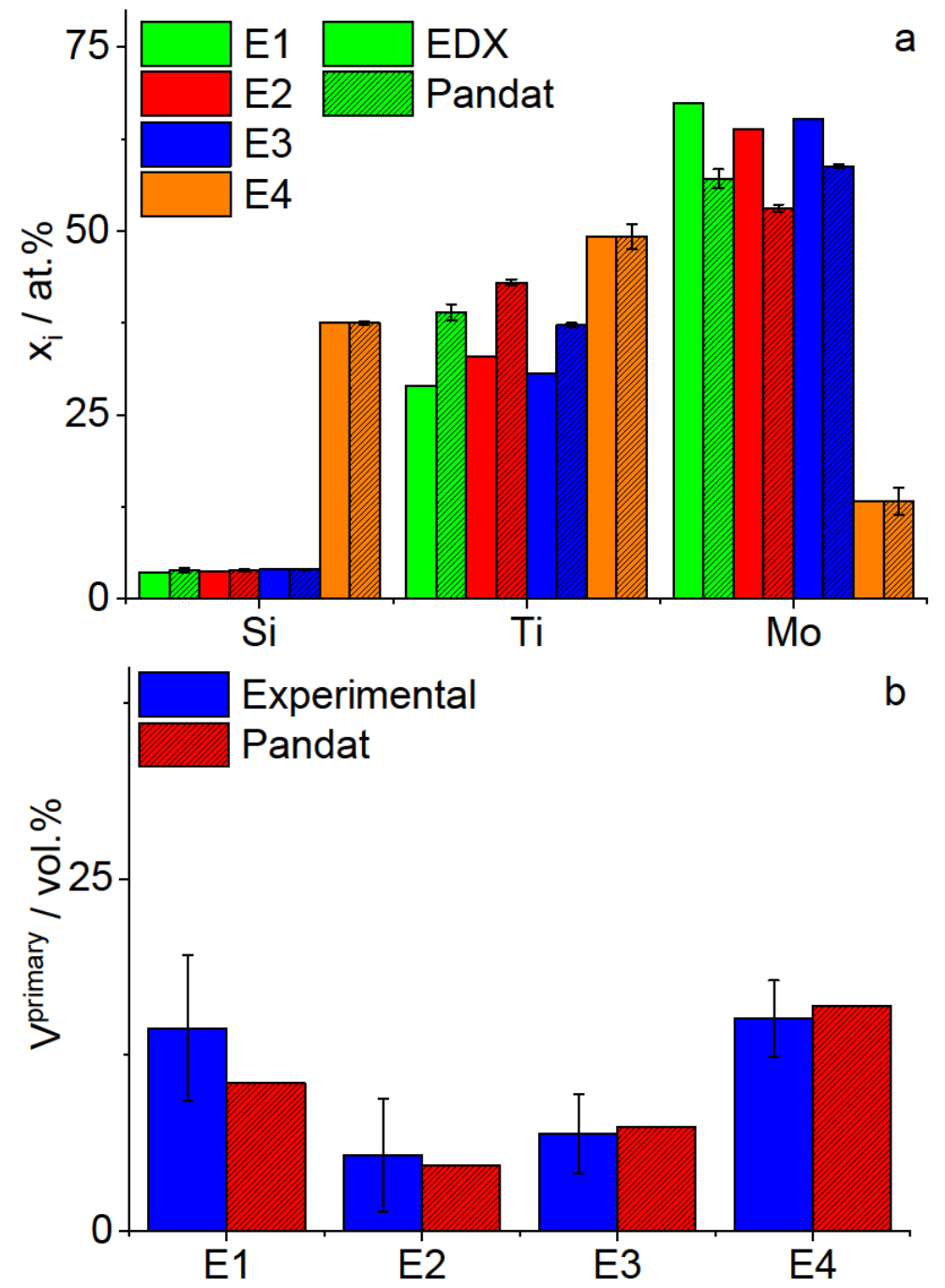

Figure 2: Comparison of the prediction by thermodynamic calculation and experimental observations: (a) composition of the primary phase and (b) volume fraction of the primary phase.

Since the validity of the simulation was verified, further alloy selection was performed based on the liquidus projection provided by Pandat. Alloy E5 with 27.2 at.\% Mo, 20.0 at.\% Si and 52.8 at.\% Ti was manufactured and a representative SEM micrograph of the as-cast microstructure is shown in

Fig. 3a. An almost fully eutectic microstructure is observed. Only approximately $(3 \pm 1)$ vol.\% of 
140 primarily solidified ( $\mathrm{Ti}, \mathrm{Mo})_{5} \mathrm{Si}_{3}$ mostly located at the center regions of the eutectic cells is detectable.

141 The diffraction pattern in Fig. 3b further confirms the formation of the expected phases (Mo,Ti,Si) and

$142(\mathrm{Ti}, \mathrm{Mo})_{5} \mathrm{Si}_{3}$ only.

143 The thermodynamic calculations yield an 53 vol.\% to 47 vol.\% ratio of ( $\mathrm{Mo}, \mathrm{Ti}, \mathrm{Si})$ and $(\mathrm{Ti}, \mathrm{Mo})_{5} \mathrm{Si}_{3}$,

144 respectively, at an estimated density of about $6.25 \mathrm{~g} / \mathrm{cm}^{3}$. The estimated density is in good agreement

145 with the experimental density by Archimedes principle of $6.2 \mathrm{~g} / \mathrm{cm}^{3}$. The $\mathrm{Si}$ content in (Mo,Ti,Si)

146 according to thermodynamic calculations is about 2.6 at.\% when the eutectic reaction starts and

147 reduces to about 0.5 at. $\%$ when the temperature is slowly decreased below $1000{ }^{\circ} \mathrm{C}$. The Ti contents in

148 (Mo,Ti,Si) and (Ti,Mo) $)_{5} \mathrm{Si}_{3}$ are about 50 and 55 at.\%, respectively. Mo content is 47 and 7 at.\%,

149 respectively. Experimental verification of both the volume fractions as well as compositions of the

150 phases contributing to the eutectic microstructure is not suitable by the applied experimental methods

151 used in this paper due to the small lateral dimensions of the phases. 

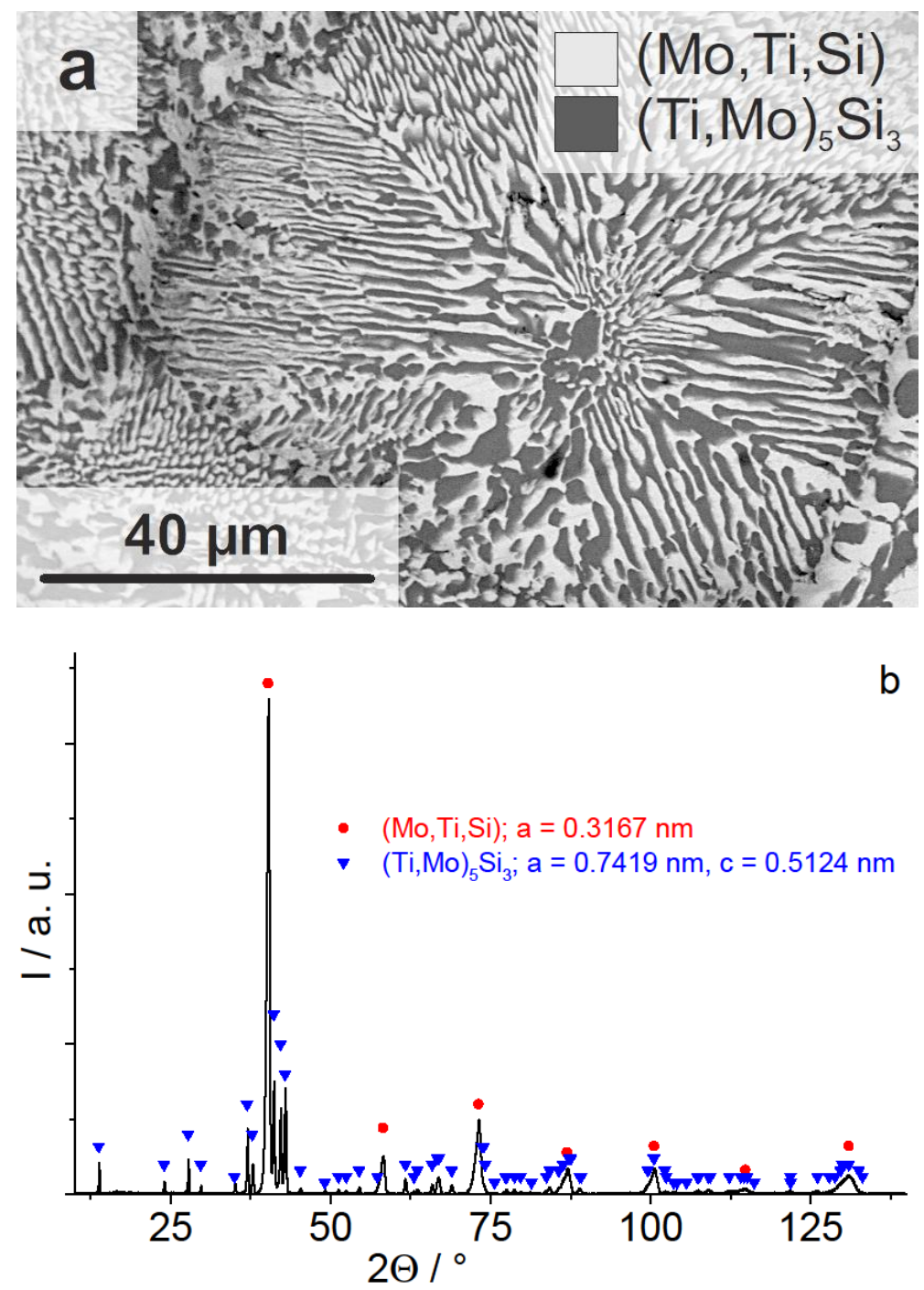

Figure 3: (a) Representative SEM micrograph (BSE contrast) and (b) XRD pattern indicating (Mo,Ti,Si) and (Ti,Mo) $)_{5} \mathrm{Si}_{3}$ phases in the fully eutectic Mo27.2-Si20.0-Ti52.8 alloy.

152

\section{Eutectoid alloy}

In the case of the eutectoid decomposition of $(\mathrm{Mo}, \mathrm{Ti})_{3} \mathrm{Si}$, the thermodynamic assessment of suitable compositions is more challenging. First of all, a monolithic solidification of $(\mathrm{Mo}, \mathrm{Ti})_{3} \mathrm{Si}$ has to be realized. Already in the case of the binary Mo-Si system, $\mathrm{Mo}_{3} \mathrm{Si}$ does not have the stoichiometric composition. Instead, the actual Si content is reduced to approximately 23.5 to 24 at.\% [21] presumably due to an incommensurate modulation of the crystal structure [22]. This has to be taken into account in order to avoid primary solidification of $(\mathrm{Mo}, \mathrm{Ti})_{5} \mathrm{Si}_{3}$. As it turns out, in the current thermodynamic description provided by the PanMo (version 2016) database, this deviation towards Silean concentrations is not considered. Thus, further simulations have been performed assuming singlephase $(\mathrm{Mo}, \mathrm{Ti})_{3} \mathrm{Si}$ subsequent to solidification at the ideal Si content of 25 at.\%. In contrast, 
experimental validation is performed on samples with lower Si content varying between 21 and 22 at.\% depending on the Ti content in order to avoid primary solidified (Mo,Ti) ${ }_{5} \mathrm{Si}_{3}$.

A second goal was to observe an eutectoid decomposition of the entire (Mo,Ti) ${ }_{3} \mathrm{Si}$ into solid solution (Mo,Ti,Si) and tetragonal $(\mathrm{Mo}, \mathrm{Ti})_{5} \mathrm{Si}_{3}$ either during cooling of the cast or during an subsequent annealing at as low as possible temperature and in an as short as possible time. Both, high temperature as well as long duration of thermal treatment may lead to coarsening of the microstructure and, thus, deterioration of the oxidation resistance because coverage of regions with solid solution by a protective scale becomes more difficult. The eutectoid decomposition is practically not observed in the case of binary Mo-Si alloys. By increasing Ti content, an increasing maximum temperature of the eutectoid reaction is suggested by the Calphad simulations. A maximum temperature of the eutectoid reaction greater than $1000{ }^{\circ} \mathrm{C}$ is obtained for Ti contents higher than 16 at.\%; it further increases to $1922{ }^{\circ} \mathrm{C}$ at 36 at.\%. Thus, the eutectoid decomposition becomes more favorable even at comparably low temperature. Indeed, Ti contents lower than 20 at.\% do not lead to considerable amounts of decomposed microstructure. In addition, density of such alloys remains rather high in comparison to Ni-base super alloys. Hence, alloys with Ti contents higher than 25 at. $\%$ are considered in what follows.

Fig. 4 compares the thermodynamic prediction by Calphad for the volume fraction of the participating phases as a function of the Ti content at $1300{ }^{\circ} \mathrm{C}$ with the experimentally observed volume fractions in samples annealed at $1300{ }^{\circ} \mathrm{C}$ for $200 \mathrm{~h}$ subsequent to casting. A similar conversion of atomic phase fraction to volume fraction based on crystallographic density as for the eutectic alloys was performed. The thermodynamic calculation predicts an entire eutectoid decomposition of $(\mathrm{Mo}, \mathrm{Ti})_{3} \mathrm{Si}$ into $(\mathrm{Mo}, \mathrm{Ti}, \mathrm{Si})$ and $(\mathrm{Mo}, \mathrm{Ti})_{5} \mathrm{Si}_{3}$ at $1300{ }^{\circ} \mathrm{C}$ for a $\mathrm{Ti}$ range between 29 and 37 at.\%. Further increase of the Ti content leads to decomposition into $(\mathrm{Mo}, \mathrm{Ti}, \mathrm{Si})$ and $(\mathrm{Ti}, \mathrm{Mo})_{5} \mathrm{Si}_{3}$ instead; at even higher Ti contents, the already investigated eutectic solidification occurs. The experimentally determined volume fractions of $(\mathrm{Mo}, \mathrm{Ti})_{3} \mathrm{Si},(\mathrm{Mo}, \mathrm{Ti}, \mathrm{Si})$ and $(\mathrm{Mo}, \mathrm{Ti})_{5} \mathrm{Si}_{3} /(\mathrm{Ti}, \mathrm{Mo})_{5} \mathrm{Si}_{3}$ subsequent to $200 \mathrm{~h}$ of annealing at $1300{ }^{\circ} \mathrm{C}$ differ significantly from the thermodynamic description. At 25 at. $\% \mathrm{Ti}$, already approximately 25 vol. $\%$ of the microstructure are decomposed - investigations on the as-cast 
microstructure reveal that the decomposition occurs only during the annealing subsequent to

manufacturing in the arc-melter and not during cooling of the as-cast ingot in the mold. In contrast, the

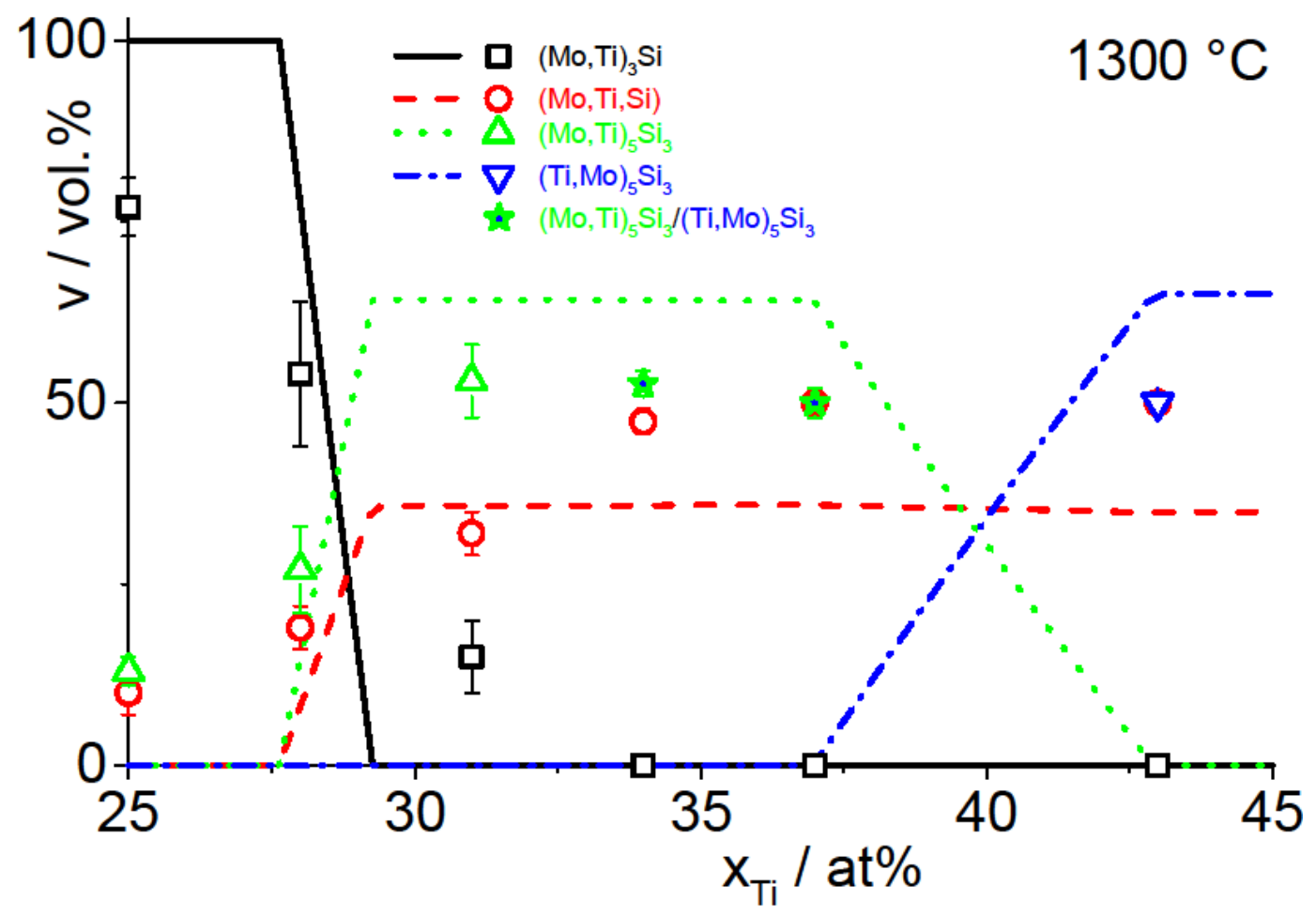

Figure 4: Comparison of the phase fraction suggested by Calphad for thermodynamic equilibrium at $1300{ }^{\circ} \mathrm{C}$ as well as volume fractions on samples heat-treated at $1300{ }^{\circ} \mathrm{C}$ for $200 \mathrm{~h}$. Note that for avoiding primary solidifying $(\mathrm{Mo}, \mathrm{Ti})_{5} \mathrm{Si}_{3}$, the actual $\mathrm{Si}$ content of the samples is 21 at.\% while Si content is set to the ideal stoichiometry of $(\mathrm{Mo}, \mathrm{Ti})_{3} \mathrm{Si}$ of 25 at.\% for the simulation. Stars denote two alloys where within silicide lamellae both tetragonal $(\mathrm{Mo}, \mathrm{Ti})_{5} \mathrm{Si}_{3}$ and hexagonal $(\mathrm{Ti}, \mathrm{Mo})_{5} \mathrm{Si}_{3}$ appear. 

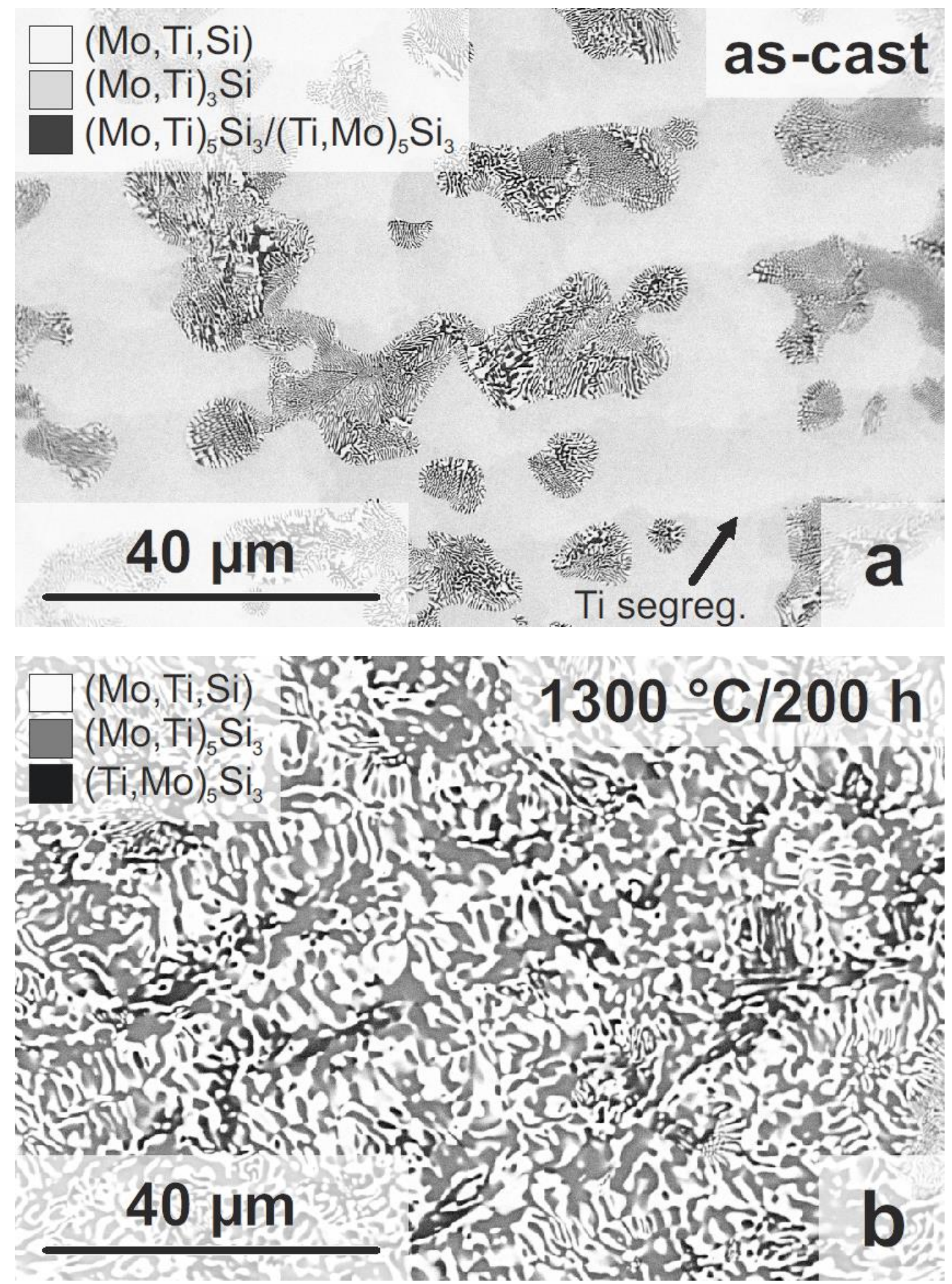

Figure 5: SEM micrographs (BSE contrast) of Mo45-Si21-Ti34 alloy in two different conditions: (left) partially, eutectoid after cooling the as-cast rod and (right) fully decomposed subsequent to heat treatment at $1300{ }^{\circ} \mathrm{C}$ for $200 \mathrm{~h}$.

Fig. 5 presents representative micrographs of the microstructures of that alloy subsequent to casting as

well as after heat-treatment at $1300{ }^{\circ} \mathrm{C}$ for $200 \mathrm{~h}$. In case of the as-cast microstructure in Fig. 5a, already a certain amount of decomposed microstructure is observed in combination with slight $\mathrm{Ti}$ segregation at the rims of the $(\mathrm{Mo}, \mathrm{Ti})_{3} \mathrm{Si}$ dendrites. It is assumed that the decomposition occurs during cooling of the cast and starts at the Ti enrichment between the dendrites. This is in accordance with the 
predicted higher decomposition temperature with increasing Ti content. Fig. $5 \mathrm{~b}$ reveals the decomposition of the (almost) entire microstructure subsequent to annealing at $1300{ }^{\circ} \mathrm{C}$ for $200 \mathrm{~h}$. The solidification of $(\mathrm{Mo}, \mathrm{Ti})_{3} \mathrm{Si}$ occurs dendritic. Therefore, varying dendrite arm spacing depending on the actual cooling conditions can be obtained. Since the decomposition reaction always starts at the Tienriched rims of the dendrites, complete decomposition is retarded in case of coarse dendrites. Thus, cooling of the casting has to be controlled for upscaling of the proposed alloying strategy. In addition, varying grey scale values within the dark phase(s) in Fig. 5 b indicate that $\left(\mathrm{Mo}, \mathrm{Ti}_{5}\right)_{5} \mathrm{Si}_{3}$ is not solely formed which was further verified by XRD in Fig. 6. Beside tetragonal (Mo,Ti) ${ }_{5} \mathrm{Si}_{3}$, some hexagonal $(\mathrm{Ti}, \mathrm{Mo})_{5} \mathrm{Si}_{3}$ is formed, too. Quantitative EBSD analyses yield a $(\mathrm{Ti}, \mathrm{Mo})_{5} \mathrm{Si}_{3}$ volume fraction of $(9.3 \pm$ 0.8) vol.\% (please see supplementary material). This might result from the Ti segregations in the ascast microstructure as is suggested by a comparison of Figs. 5a and b.

For an alloy containing 34 at.\% Ti in total, the Pandat simulation yields a volume fraction of silicide phase (due to the ideal situation in the simulation, the silicide is $(\mathrm{Mo}, \mathrm{Ti})_{5} \mathrm{Si}_{3}$ only) of about 65 vol.\% after entire decomposition which is higher than the experimentally observed silicide fraction (Fig. 4). The $\mathrm{Si}$ content in $(\mathrm{Mo}, \mathrm{Ti}, \mathrm{Si})$ provided by the calculations is very low in the order of 0.1 to 0.3 at. $\%$. The Ti content of $(\mathrm{Mo}, \mathrm{Ti}, \mathrm{Si})$ and $(\mathrm{Mo}, \mathrm{Ti})_{5} \mathrm{Si}_{3}$ is 19 and 42 at.\%, respectively. The Mo content is therefore 81 and 21 at.\%, respectively. Thus, both phases contain significantly lower amount of Ti in comparison to the eutectic alloy E5 (50 and 55 at.\%, respectively) according to the thermodynamic calculations. Due to the narrow length scale of the lamellae (below $1 \mu \mathrm{m}$ ) in the eutectoid microstructure, no experimental information about chemical composition of the intermetallic phases was determined by the applied characterization techniques so far.

The same situation of entire decomposition into $(\mathrm{Mo}, \mathrm{Ti}, \mathrm{Si})$ and a mixture of $\left(\mathrm{Mo}, \mathrm{Ti}_{5} \mathrm{Si}_{3}\right.$ and $(\mathrm{Ti}, \mathrm{Mo})_{5} \mathrm{Si}_{3}$ is observed for a Ti concentration of 37 at.\% but not shown here. At even higher Ti contents, the full decomposition into sole $(\mathrm{Ti}, \mathrm{Mo})_{5} \mathrm{Si}_{3}$ as the formed intermetallic phase can be verified in accordance with the Calphad prediction. Nevertheless, the amount of formed intermetallic phase differs from the prediction. 


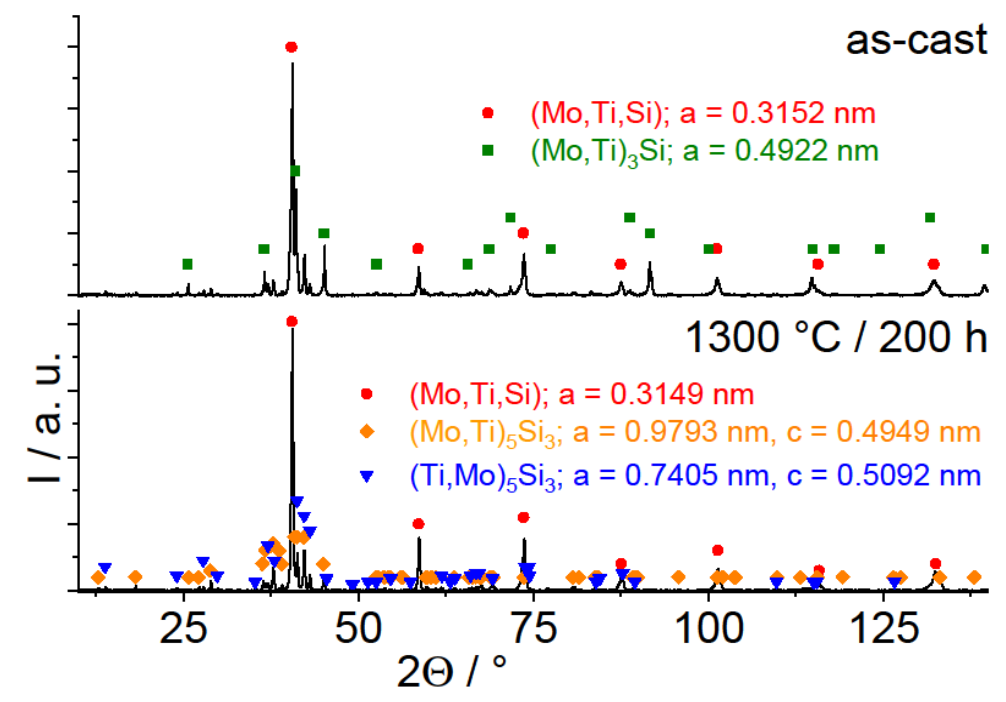

Figure 6: XRD pattern of Mo45Si21Ti34 indicating decomposition of (Mo,Ti)3Si into (Mo,Ti,Si) and (Mo,Ti) ${ }_{5} \mathrm{Si}_{3}$ during heat-treatment at $1300{ }^{\circ} \mathrm{C}$ for $200 \mathrm{~h}$. The formation of a certain amount of (Ti, Mo $)_{5} \mathrm{Si}_{3}$ is confirmed, too.

230 In the following, the oxidation behavior and the creep behavior of two representative alloys from the

231 preceding alloy development are presented and discussed. These are: (i) a fully eutectic as-cast alloy

232 with the composition of Mo27.2-Si20.0-Ti52.8 and (ii) an entirely eutectoid decomposed alloy with

233 Mo45-Si21-Ti34. For the sake of simplicity, the first alloy will be referred to as eutectic alloy and the

234 other one as eutectoid alloy.

\section{Oxidation Behavior}

236 The oxidation behavior under isothermal and cyclic oxidation conditions in terms of area specific mass change as a function of time at various temperatures $\left(800,1100\right.$ and $\left.1200{ }^{\circ} \mathrm{C}\right)$ in air is summarized in

238 Fig. 7 for both alloys. An almost negligible, positive mass change at $800{ }^{\circ} \mathrm{C}$ was observed for the eutectic alloy which is entirely composed of bcc $(\mathrm{Mo}, \mathrm{Ti}, \mathrm{Si})$ and hexagonal $(\mathrm{Ti}, \mathrm{Mo})_{5} \mathrm{Si}_{3}$. The weight gains of about $2 \mathrm{mg} / \mathrm{cm}^{2}$ (isothermal) and $0.3 \mathrm{~g} / \mathrm{cm}^{2}$ (cyclic) after $100 \mathrm{~h}$ on the eutectic alloy are similar to observations by Majumdar et al. [23]. They found a small weight gain of $1.1 \mathrm{mg} / \mathrm{cm}^{2}$ for oxidation at $900{ }^{\circ} \mathrm{C}$ for $100 \mathrm{~h}$ of a powder metallurgical Mo-40Ti-30Si alloy which consists mainly of $(\mathrm{Ti}, \mathrm{Mo})_{5} \mathrm{Si}_{3}$ with a small fraction of $(\mathrm{Mo}, \mathrm{Ti})_{3} \mathrm{Si}$. In contrast, the eutectoid alloy with a lamellar microstructure of bcc (Mo,Ti,Si) and tetragonal $(\mathrm{Mo}, \mathrm{Ti})_{5} \mathrm{Si}_{3} /$ hexagonal $(\mathrm{Ti}, \mathrm{Mo})_{5} \mathrm{Si}_{3}$ exhibits a dramatic mass loss under the same conditions indicating "catastrophic" oxidation behavior. At 1100 and $1200{ }^{\circ} \mathrm{C}$, the eutectic alloy shows slight mass gain, while the eutectoid alloy reveals negligible, negative mass changes. In general, both isothermal and cyclic oxidation experiments reveal the same 
trend but with slightly more pronounced mass changes in case of isothermal oxidation. This might be

249 attributed to the flowing gas in the TGA experiment instead of a static atmosphere during thermal

250 cycling resulting in higher oxygen activation at the surface.
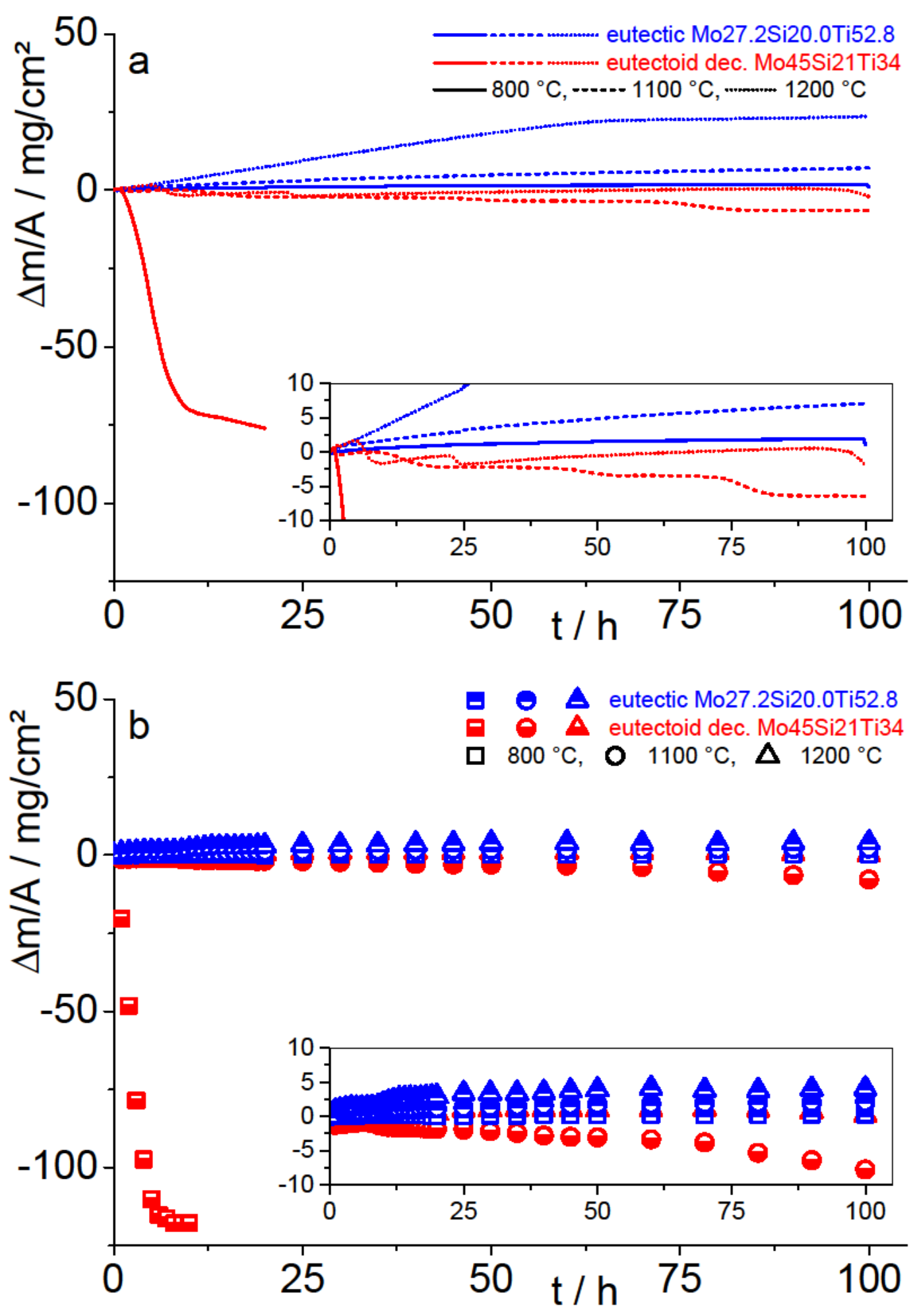

Figure 7: Specific weight change $\Delta m / A$ vs. time $t$ for (a) isothermal oxidation and (b) thermal cycling at 800 (continuous lines and square symbols), 1100 (dashed lines and circles) and $1200{ }^{\circ} \mathrm{C}$ (dotted lines and triangles), respectively. 
Cross sections were examined by SEM-BSE subsequent to oxidation under both conditions for assessment of the resulting oxide scales. Fig. 8 shows representative cross sections of the scales obtained subsequent to cyclic oxidation at 800 and $1200{ }^{\circ} \mathrm{C}$ for $100 \mathrm{~h}$ for comparison. As suggested by the observed mass change, the eutectoid alloy was completely oxidized within a range of 15 to $20 \mathrm{~h}$ during both isothermal oxidation as well as thermal cycling at $800{ }^{\circ} \mathrm{C}$. The scales on both alloys obtained after oxidation at $1100{ }^{\circ} \mathrm{C}$ are similar to the ones obtained subsequent to oxidation at $1200{ }^{\circ} \mathrm{C}$ and are therefore omitted in the overview.

For the evaluation of the microstructure of the scales, high resolution SEM-EDX maps are presented in Fig. 9. There are maps for the main constituents of the alloys, namely Mo, Si, and Ti. Furthermore, there are $\mathrm{O}$ maps provided. Due to catastrophic oxidation, the eutectoid alloy oxidized at $800{ }^{\circ} \mathrm{C}$ is omitted. The average scale thickness was determined from the SEM-BSE micrographs (Fig. 8) for thermal cycling of both alloys for $100 \mathrm{~h}$ as well. A comparison of the determined thicknesses is shown in Fig. 10.

The formed scale on the eutectic alloy during oxidation at $800{ }^{\circ} \mathrm{C}$ appears rather homogeneous in SEM-BSE images (Fig. 8a) but is indeed composed of a mixture of $\mathrm{TiO}_{2}$ and $\mathrm{SiO}_{2}$ as revealed by SEM-EDX (Fig. 9a). Unambiguous evidence for the formation of $\mathrm{TiO}_{2}$ is presented in Fig. 11a. The simulated poles and bands of rutile-type $\mathrm{TiO}_{2}$ (space group no. 136, $\mathrm{P} 4_{2} / \mathrm{m} \mathrm{n} \mathrm{m}, \mathrm{a}=4.594 \AA$ and $\mathrm{c}=$ $2.959 \AA$ A ICSD collection code 9161) perfectly match the obtained electron backscatter diffraction patterns. In agreement with the very low mass change during oxidation at $800{ }^{\circ} \mathrm{C}$, the average scale thickness for this alloy is only $(9 \pm 2) \mu \mathrm{m}$ after $100 \mathrm{~h}$ (Fig. 10). This is in the order of the scale thickness observed by Majumdar et al. [23] at $900{ }^{\circ} \mathrm{C}$ for $100 \mathrm{~h}$ which was 4 to $6 \mu \mathrm{m}$. In all cases, $\mathrm{TiO}_{2}$ forms the top-most scale (Fig. 9a) and is exposed to the atmosphere. For reference and better visibility, white lines indicate the surface of the scale and the scale-to-substrate interface. Underneath the top-most $\mathrm{TiO}_{2}$ layer, a duplex layer of $\mathrm{SiO}_{2}$ and $\mathrm{TiO}_{2}$ (crystallographic identification also yields rutile-type $\mathrm{TiO}_{2}$ ) is found. $\mathrm{SiO}_{2}$ in the lower parts of the scale preserves in most cases the morphology of the former $(\mathrm{Ti}, \mathrm{Mo})_{5} \mathrm{Si}_{3}$ silicide phase from the eutectic alloy. There is no indication for significant

277 internal oxidation under these conditions. 
The scale thickness after $100 \mathrm{~h}$ of oxidation at 1100 and $1200{ }^{\circ} \mathrm{C}$ increases to $(25 \pm 6)$ and $(68 \pm$ 15) $\mu \mathrm{m}$, respectively (Fig. 10). Furthermore, the two different parts of the scale are more distinct. Even in SEM-BSE images (Fig. 8b), rather continuous, top-most layers are observed. SEM-EDX mapping reveals again $\mathrm{TiO}_{2}$ in these regions (Fig. 9b). Crystallographic identification yields rutile-type $\mathrm{TiO}_{2}$ as shown in Fig. 11b. Underneath the top-most layer, a $\mathrm{TiO}_{2} / \mathrm{SiO}_{2}$ duplex layer with varying matrix and inclusion character of both phases is found. In addition to the scale surface and the interface to the substrate, the transition from the top-most $\mathrm{TiO}_{2}$ layer to the duplex layer is highlighted by a white line in Fig. 9b. A similar morphology was reported for $\mathrm{Ti}_{5} \mathrm{Si}_{3}$ oxidized at $100{ }^{\circ} \mathrm{C}$ for $100 \mathrm{~h}$ by Tang et al. [24] (oxidized in pure $\mathrm{O}_{2}$ ) as well as at $1200{ }^{\circ} \mathrm{C}$ for $100 \mathrm{~h}$ by Mitra and Rama Rao [25]. The zone of internal diffusion is limited to less than $10 \mu \mathrm{m}$. The microstructure of the oxide scale formed at $1200{ }^{\circ} \mathrm{C}$ on the eutectic alloy was further analyzed by EBSD. The orientation map for rutile-type $\mathrm{TiO}_{2}$ is presented in Fig. 11c. Black pixels indicate un-indexed portions of the map and mostly correspond to (amorphous or nanocrystalline) $\mathrm{SiO}_{2}$. The top-most $\mathrm{TiO}_{2}$ layer is composed of columnar grains which span over the entire ( $\mathrm{TiO}_{2}$ top-)layer with a thickness of about $20 \mu \mathrm{m}$. Underneath the top-most layer, the grain size of $\mathrm{TiO}_{2}$ gradually decreases towards the substrate and a varying matrix and inclusion character of the two participating oxide phases $\mathrm{SiO}_{2}$ and $\mathrm{TiO}_{2}$ is confirmed. This is in contrast to the observations by Tang et al. [24] for oxidation of $\mathrm{Ti}_{5} \mathrm{Si}_{3}$ in flowing pure $\mathrm{O}_{2}$, who found the inner layer consisting of continuous $\mathrm{SiO}_{2}$ with dispersed $\mathrm{TiO}_{2}$ particles. They also reveal an impact of $\mathrm{N}$ on the oxidation behavior of stoichiometric $\mathrm{Ti}_{5} \mathrm{Si}_{3}$ in later stages of oxidation. In the present case,

297 there is no evidence for nucleation and growth of a TiN subscale by SEM-EDX or SEM-EBSD.

298 Nevertheless, it has to be mentioned that Ti-L $(0.452 \mathrm{keV})$ and N-K $(0.392 \mathrm{keV})$ lines are partially overlapping and unambiguous results on the distribution of $\mathrm{N}$ within the scales is difficult to be achieved by the applied characterization techniques. 

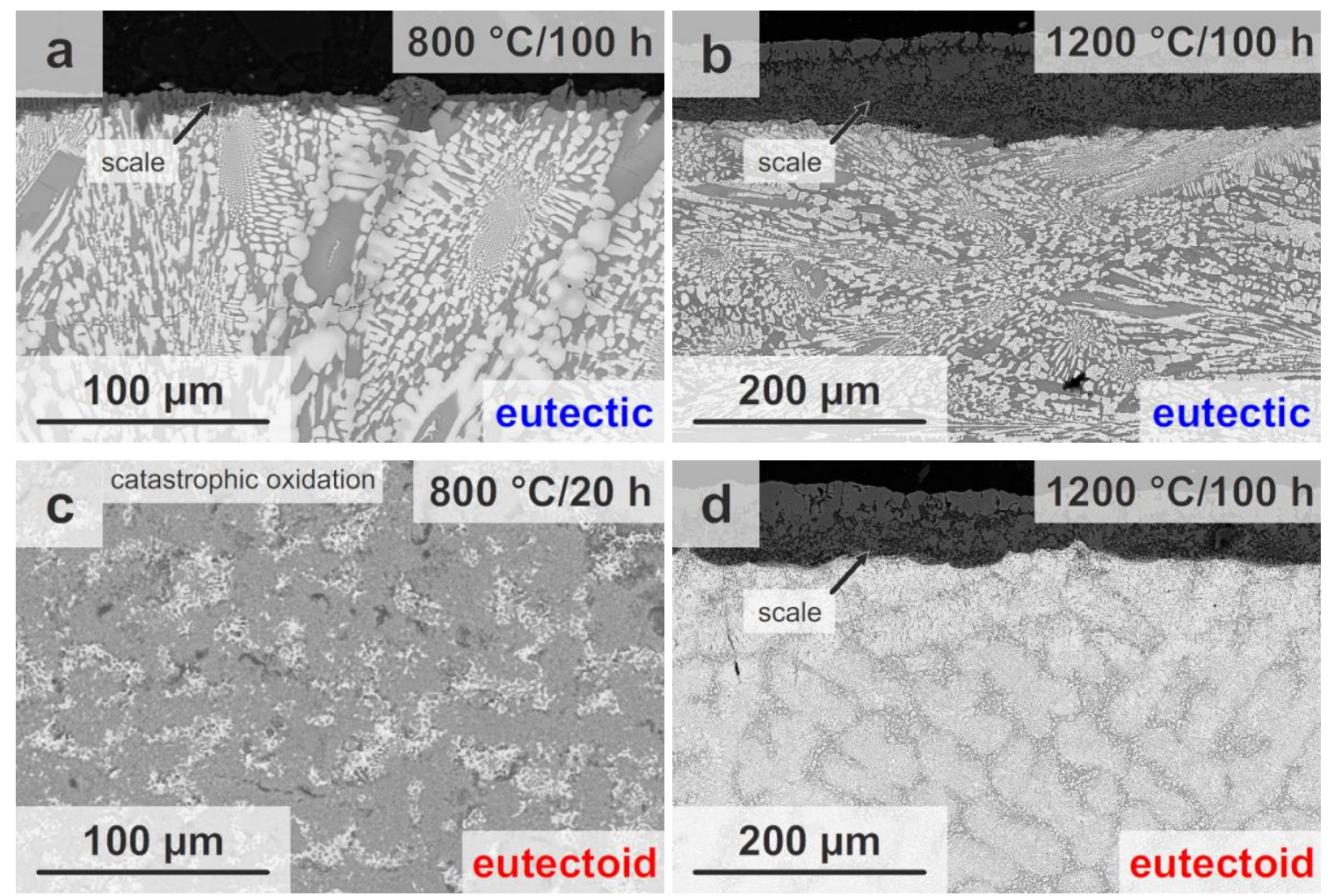

Figure 8: Micrographs of the scale cross sections subsequent to cyclic oxidation at 800 (a, c) and $1200{ }^{\circ} \mathrm{C}(\mathrm{b}, \mathrm{d})$ for the eutectic $(\mathrm{a}, \mathrm{b})$ and the eutecoid $(\mathrm{c}, \mathrm{d})$ alloys. In case of $800{ }^{\circ} \mathrm{C}(\mathrm{c})$, catastrophic oxidation of the eutectoid alloy occurs within short time of approx. $20 \mathrm{~h}$. Other images are obtained after $100 \mathrm{~h}$ of oxidation. 

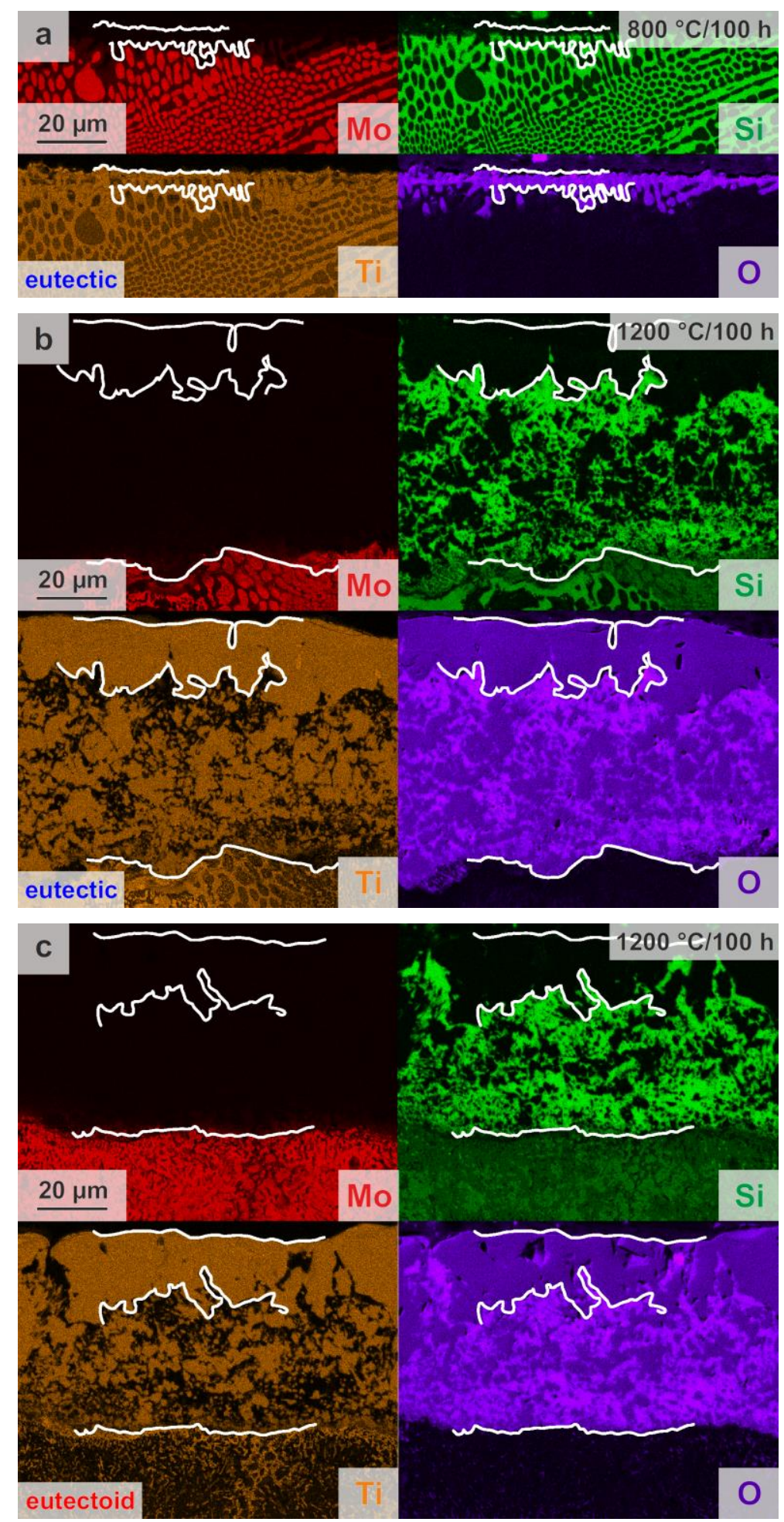

Figure 9: SEM-EDX maps of the scale cross sections subsequent to $100 \mathrm{~h}$ of cyclic oxidation at a) 800 and b) $1200{ }^{\circ} \mathrm{C}$ both of which for the eutectic alloy as well as c) $1200{ }^{\circ} \mathrm{C}$ for the eutectoid alloy. White lines indicate the substrate/scale interface, the transition from $\mathrm{TiO}_{2} / \mathrm{SiO}_{2}$ to $\mathrm{TiO}_{2}$ and the surface of the scale, respectively. 


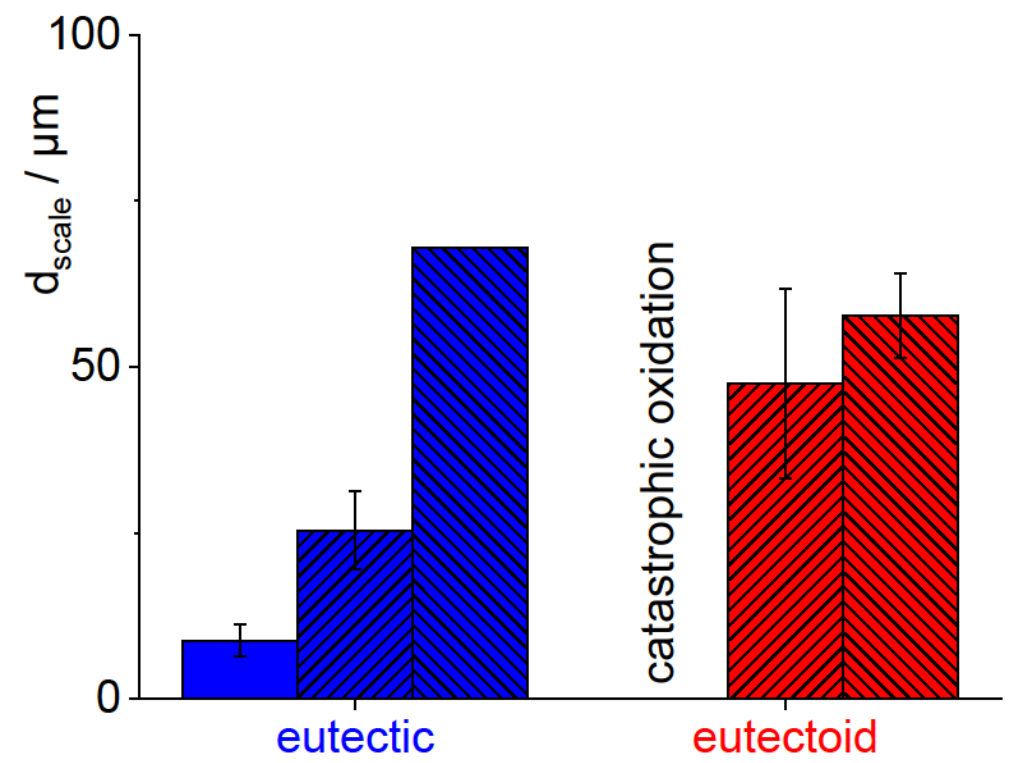

Figure 10: Scale thickness $d_{\text {scale }}$ subsequent to $100 \mathrm{~h}$ of cyclic exposure to air at 800,1100 and $1200{ }^{\circ} \mathrm{C}$ for the eutectic and the eutectoid material.
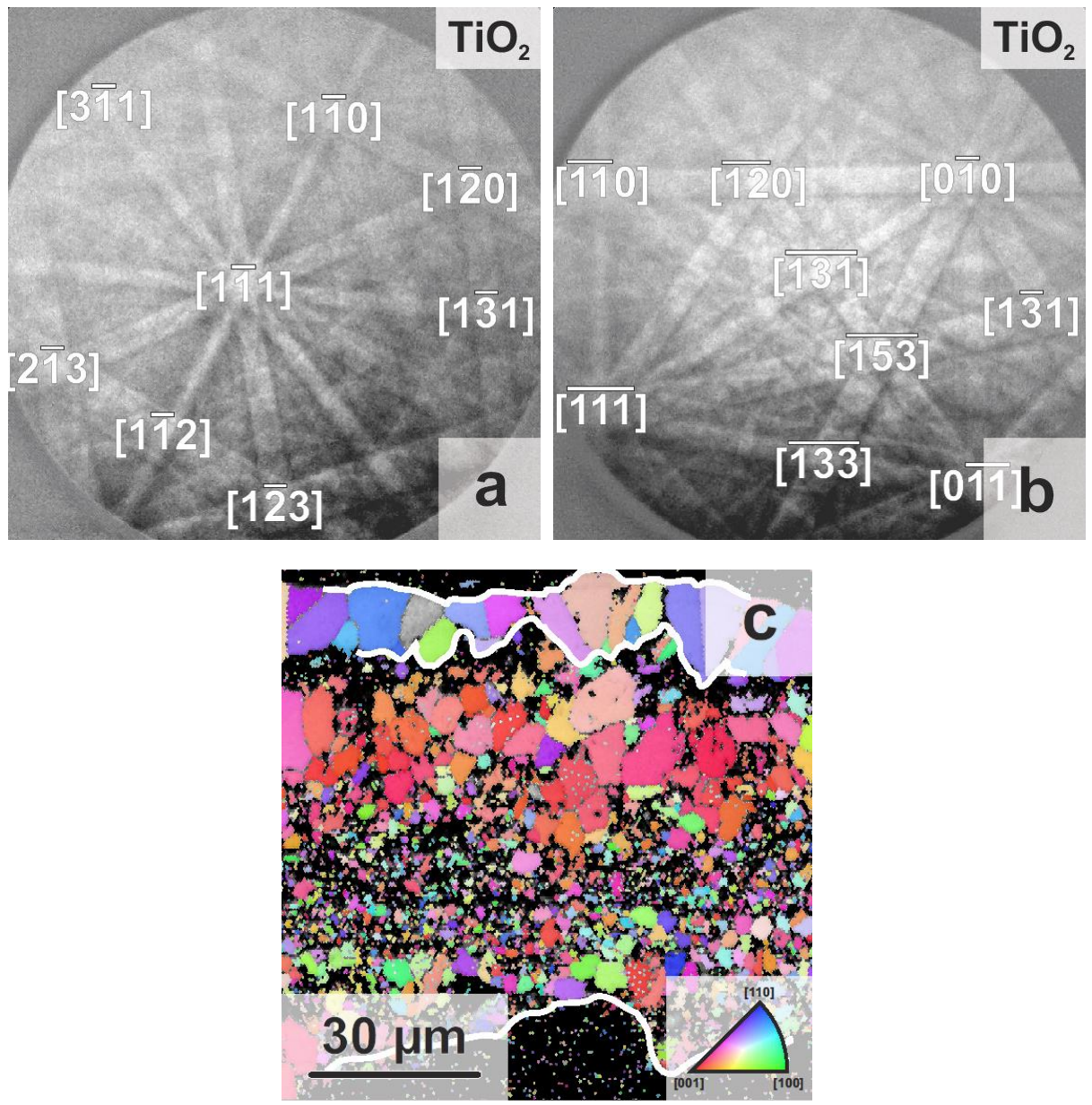

Figure 11: Representative electron backscatter diffraction patterns collected from the oxide scales on the eutectic alloy after $100 \mathrm{~h}$ of oxidation at: a) $800{ }^{\circ} \mathrm{C}$ and b) $1200{ }^{\circ} \mathrm{C}$. Some selected poles are highlighted according to the orientation determination. c) Orientation map obtained on the cross section of the oxide scale on the eutectic alloy after oxidation with the conditions in b). White lines are drawn to guide the eyes as in Fig. 9. 
For the eutectoid alloy, the oxide formed during catastrophic oxidation at $800{ }^{\circ} \mathrm{C}$ consists mainly of

303

304 $\mathrm{TiO}_{2}$ with some embedded $\mathrm{SiO}_{2}$ particles and some remaining (Mo,Ti,Si) solid solution. Compared to the eutectic alloy, scale morphology (Figs. 8b vs. 8d, Figs. 9b vs. 9c) and thickness (Fig. 10) on the eutectoid alloy after $100 \mathrm{~h}$ of oxidation at 1100 and $1200^{\circ} \mathrm{C}$ is very similar, exhibiting an outer $\mathrm{TiO}_{2}$ scale with a $\mathrm{TiO}_{2} / \mathrm{SiO}_{2}$ duplex layer underneath. However, the internal oxidation zone of the eutectoid alloy is much thicker than that of the eutectic alloy, namely up to $90 \mu \mathrm{m}$ at $1200{ }^{\circ} \mathrm{C}$ instead of about $10 \mu \mathrm{m}$ for the eutectic alloy. Thus, the $\mathrm{TiO}_{2} / \mathrm{SiO}_{2}$ duplex layer seems to be less dense and allows faster inward transport of $\mathrm{O}$.

There are several influences on the oxidation behavior in the present cases which have to be considered during the interpretation of the obtained results. These are for example: (i) thermodynamic stability of the oxide phases, (ii) fraction, dimensions and distribution of non-protective phases, (iii) viscosity of the scales, (iv) growth rate of the oxide phases, (v) inward diffusion of $\mathrm{O}$ to form an internal oxidation zone and outward diffusion of $\mathrm{Ti}^{4+}$ to form the top-most $\mathrm{TiO}_{2}$ layer, (vi) disturbance of scale growth by the evaporation of $\mathrm{MoO}_{3}$, and finally (vii) changing composition at the interfaces by scale formation.

Throughout the temperature range under investigation, $\mathrm{TiO}_{2}$ formation is in principle more favorable over $\mathrm{SiO}_{2}$ formation due to the more negative free energy of formation [25]. Nevertheless, free energy of formation is comparable at 1100 and $1200{ }^{\circ} \mathrm{C}$ (slight difference of only $\sim 13 \mathrm{~kJ} / \mathrm{mol}$ ) which allows a simultaneous formation of $\mathrm{SiO}_{2}$ and $\mathrm{TiO}_{2}$ at 1100 and $1200{ }^{\circ} \mathrm{C}$. The outer $\mathrm{TiO}_{2}$ layer can be traced back to a faster growth rate of $\mathrm{TiO}_{2}$ compared to $\mathrm{SiO}_{2}$. The latter allows $\mathrm{Ti}^{4+}$ ions to diffuse through the $\mathrm{TiO}_{2} / \mathrm{SiO}_{2}$ duplex layer to the $\mathrm{TiO}_{2}$ scale that leads to a further growth of the outer $\mathrm{TiO}_{2}$ scale [26]. At temperatures below about $830^{\circ} \mathrm{C}$, the free energy of formation of $\mathrm{TiO}_{2}$ is significantly more negative than that for $\mathrm{SiO}_{2}$ (difference of $34 \mathrm{~kJ} / \mathrm{mol}[26]$ ). A preferred formation of $\mathrm{TiO}_{2}$ is therefore observed. Nevertheless, $\mathrm{SiO}_{2}$ forms in the vicinity of the former silicide phase as it is shown in Fig. 9a. An Si content higher than 40 at.\% is typically assumed for the formation of protective $\mathrm{SiO}_{2}$ on Tibased materials [27]. In the present case, the increase of the Si content in the silicide phase from 35.6 at.\% (SEM-EDX, Fig. 2) or 37.5 at.\% (thermodynamic calculations) to more than 40 at.\% might 
locally be driven by the $\mathrm{Ti}$ depletion following the $\mathrm{TiO}_{2}$ formation in the initial stages of oxidation.

330 The situation might be similar to the conditions which lead to the formation of a continuous $\mathrm{SiO}_{2}$

331 matrix with embedded $\mathrm{TiO}_{2}$ particles on Mo-40Ti-30Si which mainly consists of $(\mathrm{Ti}, \mathrm{Mo})_{5} \mathrm{Si}_{3}$ by

332 Majumdar et al. [23] for oxidation at $900{ }^{\circ} \mathrm{C}$ for $100 \mathrm{~h}$. In the present case, the protectiveness of the

$333 \mathrm{SiO}_{2}$ network for the entire substrate (incl. the non-protective (Mo,Ti,Si) solid solution) depends on

334 the distribution of the silicide phase within the eutectic. This has to be investigated in more detail in

335 future. Nevertheless, that the formed scale on the eutectic alloy successfully suppresses the formation

336 of volatile $\mathrm{MoO}_{3}$ is further supported by oxidation tests at $800{ }^{\circ} \mathrm{C}$ up to $1000 \mathrm{~h}$. Even under these

337 conditions, no catastrophic oxidation of the eutectic alloy is observed and the oxide scale remains

338 rather thin in the same order of magnitude as observed after $100 \mathrm{~h}(\sim 20 \mu \mathrm{m}$; please see supplementary

339 material).

340 For both types of alloys, a similar fraction of silicide(s) and solid solution is found (both in the order

341 of 50 vol.\%, see section "Alloy Development"). Therefore, this does not play a crucial role for the

342 seemingly different oxidation behavior at $800{ }^{\circ} \mathrm{C}$ in the present cases. Furthermore, the lateral

343 dimensions of the non-protective ( $\mathrm{Mo}, \mathrm{Ti}, \mathrm{Si})$ solid solution is significantly smaller in the case of the

344 catastrophically failing, eutectoid alloy. Therefore, the process of coverage of the solid solution by a

345 potentially protective scale is also not decisive. This might be addressed by further B addition for

346 lowering of the scale viscosity in the future which might also improve the oxidation behavior at

$347 \quad 1100$ and $1200{ }^{\circ} \mathrm{C}$ for the eutectoid alloy.

348 The most notable difference between the eutectic and eutectoid alloy is the Ti content solved in both,

349 the silicide(s) and the solid solution. It is several times higher in the case of the eutectic alloy

350 (55/50 at.\% in the eutectic alloy vs. $42 / 19$ at.\% in the eutectoid, respectively); the Mo content is

351 therefore much smaller (7/47 at.\% in the eutectic vs. 21/81 at.\% in the eutectoid alloy, respectively).

352 As stated by Majumdar et al. [23], the thermodynamic probability for the formation of $\mathrm{MoO}_{3}$ might be

353 much smaller when compared to $\mathrm{TiO}_{2}$ and $\mathrm{SiO}_{2}$ due to a small Mo activity at lower Mo content. A

354 continuous evaporation of $\mathrm{MoO}_{3}$ throughout the investigated temperature range from 800 to $1200{ }^{\circ} \mathrm{C}$

355 can contribute to a disturbance of a stable scale growth. This disturbance might be more pronounced at 
low temperatures where the kinetics of scale formation is generally slower. The higher Mo content in the eutectoid alloy might therefore prevent the formation of any protective scale. This also agrees with the rather small weight changes observed at 1100 and $1200{ }^{\circ} \mathrm{C}$ for both alloys. A constant mass change over time (which might imply a protective oxide scale) can be established by simultaneous formation of $\mathrm{TiO}_{2} / \mathrm{SiO}_{2}$ and evaporation of $\mathrm{MoO}_{3}$. When both effects are balanced accordingly, small weight changes in area specific mass change vs. time plots can be pretended. Thus, attention has to be paid on scale morphology and thickness after certain amount of time before drawing conclusions on scale protectiveness. The evaporation of $\mathrm{MoO}_{3}$ seems to be more pronounced in the case of the Mo-rich, eutectoid alloy at 1100 and $1200{ }^{\circ} \mathrm{C}$ since the mockup and thickness of the scales is similar to the eutectic alloy while the eutectoid alloy possesses slight weight loss and the eutectic slight weight gain. This might be indicative for a more pronounced $\mathrm{MoO}_{3}$ evaporation for the higher Mo content in the eutectoid alloy.

Most of the alloys reported in literature and also the eutectoid one investigated here show the formation of a $\mathrm{TiO}_{2} / \mathrm{SiO}_{2}$ duplex layer where $\mathrm{SiO}_{2}$ is not continuous. Only single-phase alloys like Mo-37Si-40Ti consisting of (Mo,Ti $)_{5} \mathrm{Si}_{3}$ [13], Mo-13.8Si-23.6B-25Ti consisting of $\left(\mathrm{Mo}, \mathrm{Ti}_{5} \mathrm{SiB}_{2}[28]\right.$, or the aforementioned almost single-phase Mo-40Ti-30Si which mainly consists of (Ti,Mo ${ }_{5} \mathrm{Si}_{3}[23]$ form a continuous $\mathrm{SiO}_{2}$ scale with embedded $\mathrm{TiO}_{2}$ particles under certain circumstances. As a consequence, very low weight gains as typical for silica forming alloys have been observed over a wide temperature range from 750 to $1300^{\circ} \mathrm{C}$ in these cases [28]. This suggests that the presence of Mo-rich solid solution can disturb the $\mathrm{SiO}_{2}$ scale formation; probably due to the evaporation of $\mathrm{MoO}_{3}$. In both investigated cases, the volume fraction of solid solution is about $50 \mathrm{vol} . \%$ and is not decisive for the observed oxidation behavior (thermodynamic calculation for the eutectic alloy; experimentally

378 observed fraction in the case of the eutectoid alloy in Fig. 4). Therefore, the significance of the total

379 Mo content is further proven. The situation might be facilitated due to the considerably higher local Mo content of the solid solution of the eutectoid alloy. 


\section{Creep Behavior}

382 Fig. 12 shows representative compression creep curves of both alloys at $1200^{\circ} \mathrm{C}$ and for an applied true stress of $150 \mathrm{MPa}$. For each testing condition, a minimum strain rate $\dot{\varepsilon}_{m}$ was detected (marked by circles in Fig. 12). The minimum creep rates for both alloys were typically attained after a substantial drop in creep rate during the primary transient at plastic strains between 0.01 and 0.02 . However, the strain acceleration after the minimum is less than a factor of 2 for the eutectic alloy and a factor of 4 for eutectoid material at about $9 \%$ true plastic strain. This is a comparable behavior to previously tested multiphase Mo-Si-B-Ti alloys which consist of Mo solid solution, $\mathrm{Mo}_{5} \mathrm{SiB}_{2}, \mathrm{Mo}_{3} \mathrm{Si}_{\text {and }} \mathrm{Ti}_{5} \mathrm{Si}_{3}$ $[9,28]$.

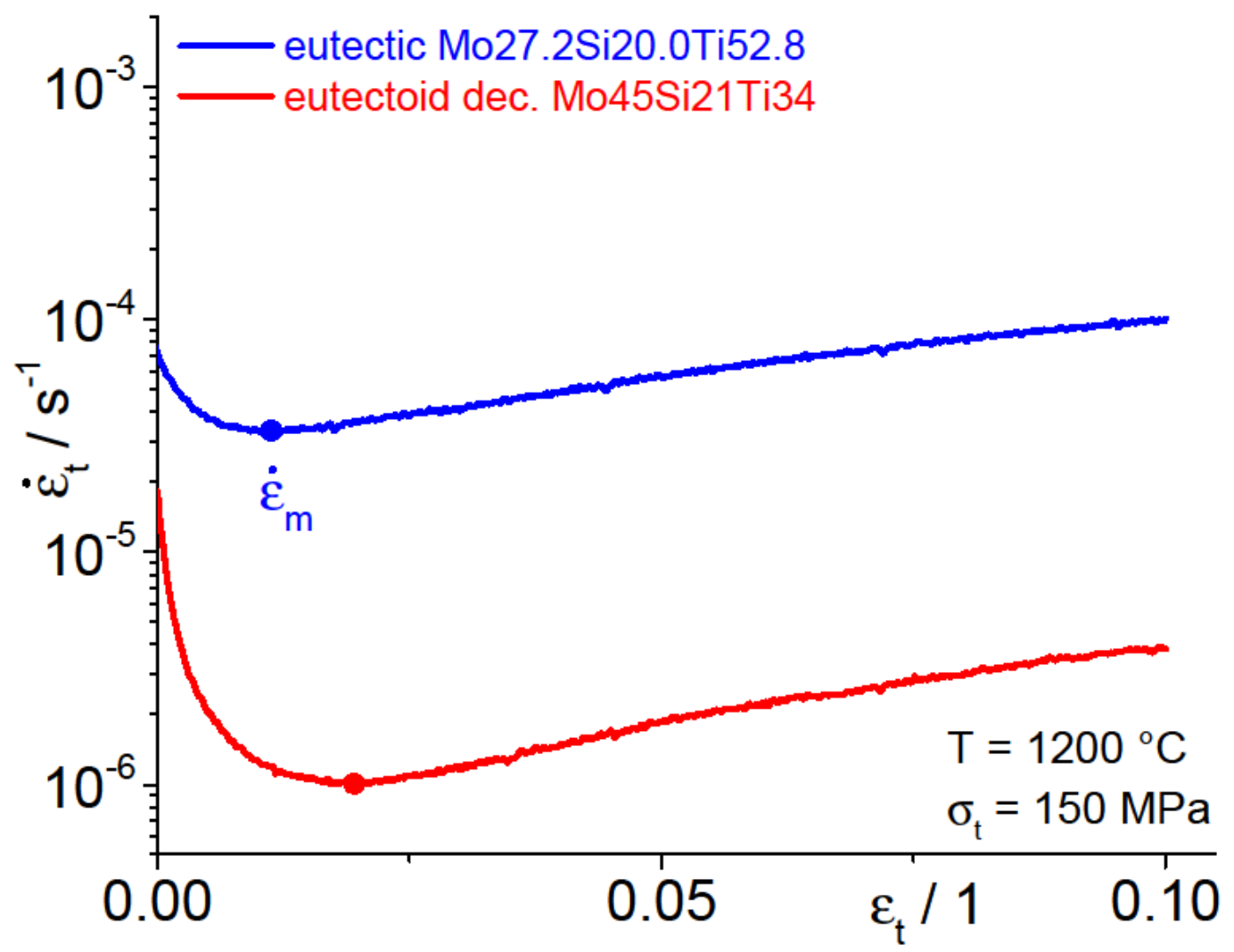

Figure 12: Comparison of representative creep curves at $1200^{\circ} \mathrm{C}$ and an applied true stress of $150 \mathrm{MPa}$.

Minimum creep rates of both alloys are subsequently plotted as a function of the applied true stress in

Fig.13. One can clearly state for the whole stress range tested that for the eutectoid alloy the creep rates are more than one order of magnitude lower than for the eutectic alloy, cf. the red circles and blue squares in Fig. 13. For comparison, the creep behavior of monolithic (binary), hexagonal $\mathrm{Ti}_{5} \mathrm{Si}_{3}$ and tetragonal $\mathrm{Mo}_{5} \mathrm{Si}_{3}$ are also shown as green triangles and purple diamond symbols, respectively. In 
what follows, we assess the contribution of the individual phases present in the respective alloys to creep deformation by comparison to the monolithic, binary silicides.

397 The creep resistance of the hexagonal $\mathrm{Ti}_{5} \mathrm{Si}_{3}$ is well known from literature $[29,30]$. The creep rate 398 reported in Ref. [30] at $1200{ }^{\circ} \mathrm{C}$ is almost identical to what was obtained for the eutectic alloy in the 399 present work as it is shown in Fig. 13a. There are only a few reported creep tests in literature for 400 binary, tetragonal $\mathrm{Mo}_{5} \mathrm{Si}_{3}$. Anton and Shah [31] determined the compression creep rate of $\mathrm{Mo}_{5} \mathrm{Si}_{3}$ in 401 the range of the eutectoid alloy investigated here. Meyer, Kramer \& Akinc [32] showed that $\mathrm{Mo}_{5} \mathrm{Si}_{3}$ exhibits a lower compression creep rate even at $1240{ }^{\circ} \mathrm{C}$.

Qualitatively, the creep rate of the eutectic alloy seems to be strongly determined by the presence of the least creep resistant $\mathrm{Ti}_{5} \mathrm{Si}_{3}$ whereas the eutectoid alloy exhibits creep rates similar to the few available experimental results on $\mathrm{Mo}_{5} \mathrm{Si}_{3}$. Furthermore, the latter results are also similar to other Mobased multiphase materials where Mo solid solution also contributes to the creep deformation to significant extent. As in the case of the oxidation behavior of the present alloys, the Mo content of the respective alloys might play a role for the creep resistance as well. The eutectoid alloy with its higher

409 Mo content also exhibits a higher melting point (liquidus temperature of $2100{ }^{\circ} \mathrm{C}$ for the eutectoid 410 alloy vs. $1930{ }^{\circ} \mathrm{C}$ for the eutectic alloy, respectively; solidus temperature about 150 to $200 \mathrm{~K}$ below 411 that), which leads to a lower homologous temperature when testing at $1200{ }^{\circ} \mathrm{C}$ in comparison to the eutectic alloy. 

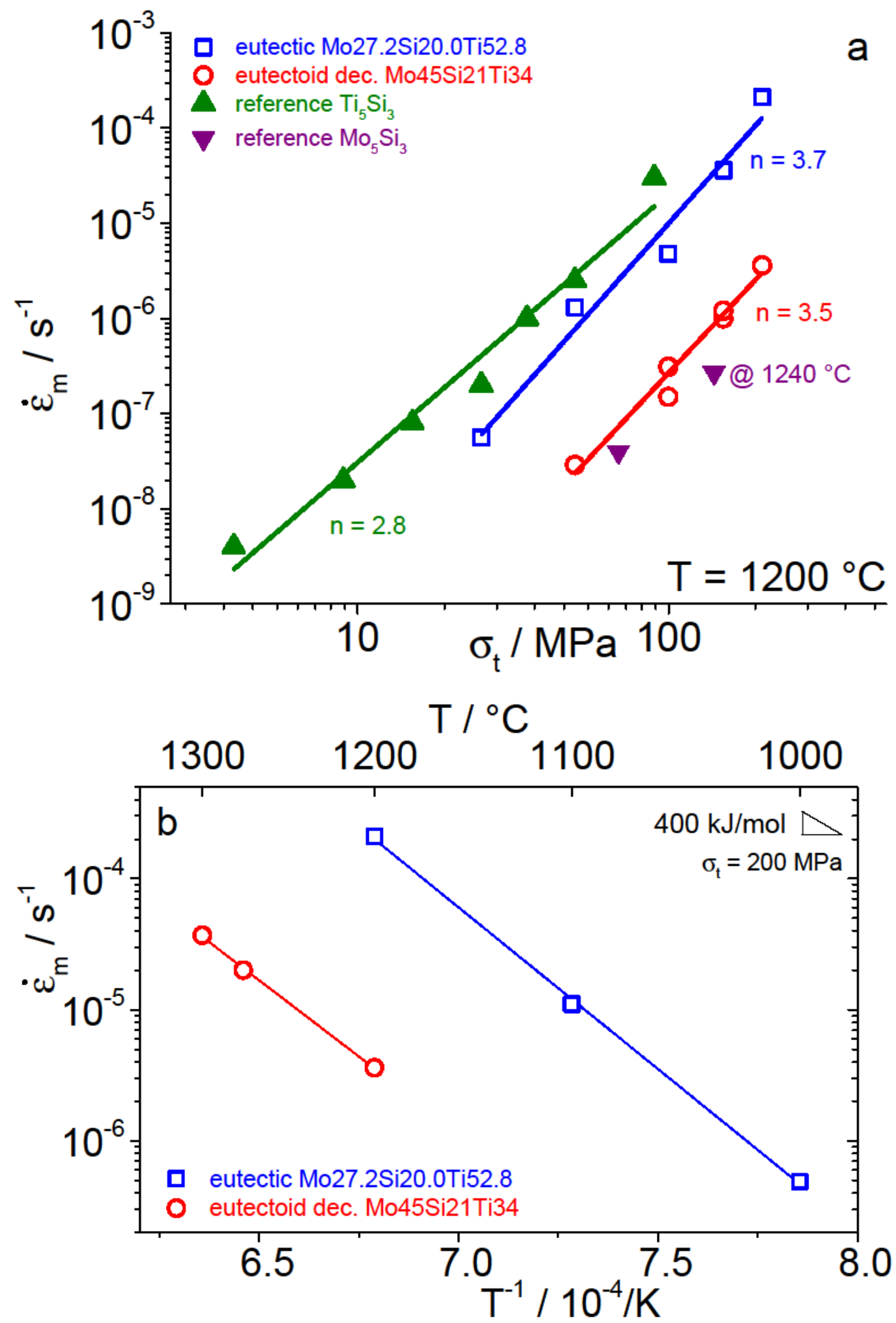

Figure 13: (a) Norton plot at $1200{ }^{\circ} \mathrm{C}$ (double logarithmic, minimum true strain rate vs. applied true stress) and (b) Arrhenius plot (logarithmic, minimum true strain rate vs. inverse absolute temperature). Data for monolithic $\mathrm{Ti}_{5} \mathrm{Si}_{3}$ and $\mathrm{Mo}_{5} \mathrm{Si}_{3}$ are taken from Refs. [28, 30, 31].

413 The observed stress exponents of 3.7 and 3.5 for the eutectic alloy and the eutectoid alloy,

414 respectively, indicate dislocation climb controlled creep. Rosenkranz et al. [30] found a stress

415 exponent of 3 for $\mathrm{Ti}_{5} \mathrm{Si}_{3}$ in the range of 1000 to $1200{ }^{\circ} \mathrm{C}$ which was confirmed by Sadananda et al. [29] 
for $\mathrm{Ti}_{5} \mathrm{Si}_{3}$ at $1200{ }^{\circ} \mathrm{C}$. This further supports a possibly dominant contribution of $\mathrm{Ti}_{5} \mathrm{Si}_{3}$ to the creep deformation in the eutectic alloy. Compared to that, Mo-Si-B alloys show stress exponents in the range of 3 to $7[16,33,34,35,36]$ at $1200{ }^{\circ} \mathrm{C}$.

Finally, the activation energy $\mathrm{Q}_{\mathrm{c}}$ for creep was determined at a true stress of $200 \mathrm{MPa}$ using the slope of the Arrhenius plot shown in Fig. 13b. It further validates the assumption of dislocation climb controlled creep being active in the present cases. $Q_{c}$ is calculated to be $(471 \pm 13) \mathrm{kJ} / \mathrm{mol}$ for the eutectic and $(444 \pm 14) \mathrm{kJ} / \mathrm{mol}$ for the eutectoid alloy. Both values are covered by the range of data available in the literature for comparable alloys and intermetallic compounds. For example, monolithic $\mathrm{Ti}_{5} \mathrm{Si}_{3}$ shows $\mathrm{Q}_{\mathrm{c}}$ values with substantial scatter from $(320 \pm 20) \mathrm{kJ} / \mathrm{mol}$ [30] to 620 to $640 \mathrm{~kJ} / \mathrm{mol}$ [29]. For multiphase Mo-Si-B alloys activation energies of creep were found to range from 360 to $450 \mathrm{~kJ} / \mathrm{mol}[33,35,37,38,39,40]$. The latter is in good agreement with the activation energy for selfdiffusion of Mo, which is reported to be in the order of 320 to $370 \mathrm{~kJ} / \mathrm{mol}$ [41] and $405 \mathrm{~kJ} / \mathrm{mol}$ [42].

\section{Conclusions}

Calphad on the basis of the dataset by Yang et al. [17] accurately reproduces chemical composition as trends like the congruent solidification of $(\mathrm{Mo}, \mathrm{Ti})_{3} \mathrm{Si}$ and the increasing tendency of the eutectoid decomposition with increasing Ti content can be described by the thermodynamic calculations. Nevertheless, the experimentally confirmed non-stoichiometry of $(\mathrm{Mo}, \mathrm{Ti})_{3} \mathrm{Si}$ and the different volume

436 fractions of the phases after eutectoid decomposition at $1300{ }^{\circ} \mathrm{C}$ should be refined in future 437 thermodynamic models.

438 For a fully eutectic alloy with a composition of Mo27.2-Si20.0-Ti52.8 (at.\%), which consists of 439 (Mo, $\mathrm{Ti}, \mathrm{Si})$ and $(\mathrm{Ti}, \mathrm{Mo})_{5} \mathrm{Si}_{3}$ in an almost 50:50 volumetric ratio, a remarkable oxidation behavior at $440800{ }^{\circ} \mathrm{C}$ was found. It does not exhibit the well-known pesting/catastrophic oxidation behavior as found 441 for most other Mo-based alloys with large fractions of Mo-rich solid solution which were investigated 
in literature so far. Rather the formation of a $\mathrm{TiO}_{2} / \mathrm{SiO}_{2}$ oxide scale is observed. In contrast, the eutectoid Mo45-Si21-Ti34 (at.\%) which consists of (Mo,Ti,Si) and (Mo,Ti) $)_{5} \mathrm{Si}_{3}$ shows catastrophic oxidation within short time at $800{ }^{\circ} \mathrm{C}$ as it is typically observed for other Mo-Si-based materials. For higher oxidation temperatures of 1100 and $1200^{\circ} \mathrm{C}$, both alloys possess similar oxidation behavior by the formation of $\mathrm{TiO}_{2} / \mathrm{SiO}_{2}$ duplex layers covered by an outer $\mathrm{TiO}_{2}$ scale. Nevertheless, the eutectic alloy shows slight mass gain in comparison to slight mass loss in the case of the eutectoid alloy which might be related to a less pronounced evaporation of volatile $\mathrm{MoO}_{3}$. Even though the revealed behavior might not be protective, the significant suppression of the formation of volatile oxides during oxidation of the eutectic alloy despite a rather large volume fraction of Mo-rich solid solution can be a key step for further improvement of Mo-Si-Ti-based materials. The total Mo content of the alloy and the locally solved Mo content in the solid solution seem to be decisive for this suppression.

The outstandingly oxidation resistant but less creep resistant eutectic alloy exhibits a significantly lower density of only $6.2 \mathrm{~g} / \mathrm{cm}^{3}$ in comparison state-of-the-art Ni base super alloys and most other Mobased alloys developed so far. The creep resistant eutectoid alloy is in the order of $7.0 \mathrm{~g} / \mathrm{cm}^{3}$ but shows a one order of magnitude lower creep rate under the same loading conditions in comparison to CMSX4 for example.

A defined adjustment of the ( $\mathrm{Ti}, \mathrm{Mo})_{5} \mathrm{Si}_{3}$ volume fraction as well as adjustment of the lateral size of the phase arrangement seems to provide a reasonable strategy to obtain balanced creep and oxidation resistance of the present alloys.

\section{Acknowledgements}

The financial support of Deutsche Forschungsgemeinschaft (DFG) within the framework of grants no. HE 1872/28-1 and 28-2 is gratefully acknowledged. XC gratefully acknowledges the financial support by the CSC. AK thanks the Carl Zeiss Foundation for financial support by a postdoc grant. The authors acknowledge the chemical analysis by ICP-OES by T. Bergfeldt. This work was partly carried out with the support of the Karlsruhe Nano Micro Facility (KNMF, www.knmf.kit.edu), a Helmholtz 


\section{References}

[1] J. H. Perepezko, R. Sakidja and K. S. Kumar, Advanced Structural Materials: Properties, Design Optimization, and Applications, (Ed: W. Soboyejo), Boca Raton, FL: CRC Press, 2007.

[2] D. M. Dimiduk and J. H. Perepezko, "Mo-Si-B Alloys: Developing a Revolutionary TurbineEngine Material," MRS Bulletin, vol. 28, pp. 639-645, 2003.

[3] B. P. Bewlay, M. R. Jackson, P. R. Subramanian and J. C. Zhao, "A Review of Very-HighTemperature Nb-Silicide-Based Composites," Metalllurgical and Materials Transactions A, vol. 34, pp. 2043-2052, 2003.

[4] J. A. Lemberg and R. O. Ritchie, "Mo-Si-B Alloys for Ultrahigh-Temperature Structural Applications," Advanced Materials, vol. 24, pp. 3445-3480, 2012.

[5] R. Mitra, "Mechanical behaviour and oxidation resistance of structural silicides," International Materials Reviews, vol. 51, pp. 13-64, 2006.

[6] M. Krüger, D. Schliephake, P. Jain, K. S. Kumar, G. Schumacher and M. Heilmaier, "Effects of Zr Additions on the Microstructure and Mechanical Mechanical Behavior of PM Mo-Si-B Alloys," JOM, vol. 65, pp. 301-306, 2013.

[7] P. Jéhanno, M. Heilmaier and H. Kestler, "Characterization of an industrially processed Mobased silicide alloy," Intermetallics, vol. 12, pp. 1005-1009, 2004.

[8] G. Erickson, "A new, third-generation, single-crystal, casting superalloy," JOM, vol. 47, pp. 3639, 1995.

[9] D. Schliephake, M. Azim, K. v. Klinski-Wetzel, B. Gorr, H.-J. Christ, H. Bei, E. P. George and M. Heilmaier, "High-Temperature Creep and Oxidation Behavior of Mo-Si-B Alloys with High Ti Contents," Metallurgical and Materials Transactions A, vol. 45, pp. 1102-1111, 2014. 
[10] M. G. Mendiratta, T. A. Parthasarathy and D. M. Dimiduk, "Oxidation behavior of alphaMoMo3Si-Mo5SiB2 (T2) three phase system," Intermetallics, vol. 10, pp. 225-232, 2002.

[11] M. K. Meyer and M. Akinc, "Oxidation Behavior of Boron-Modified Mo5Si3 at $800^{\circ}-1300^{\circ} \mathrm{C}, "$ Journal of the American Ceramic Society, vol. 79, pp. 938-944, 1996.

[12] F. A. Rioult, S. D. Imhoff, R. Sakidja and J. H. Perepezko, "Transient oxidation of Mo-Si-B alloys - Effect of the microstructure size scale," Acta Materialia, vol. 57, pp. 4600-4613, 2009.

[13] S. Burk, B. Gorr, V. B. Trindad and H.-J. Christ, "Effect of Zr Addition on the High Temperature Oxidation Behaviour of Mo-Si-B Alloys," Oxidation of Metals, vol. 73, pp. 163-181, 2010.

[14] A. Schmitt, K. Kumar, A. Kauffmann, X. Li and F. H. M. Stein, "Creep of binary Fe-Al alloys with ultrafine lamellar microstructures," Intermetallics, vol. 90, pp. 180-187, 2017.

[15] Maruyama, K., R. Yamamoto, H. Nakakuki and N. Fujitsuna, "Effects of lamellar spacing, volume fraction and grain size on creep strength of fully lamellar TiAl alloys," Materials Science and Engineering A, Vols. 239-240, pp. 419-428, 1997.

[16] G. Hasemann, D. Kapulenko, I. Bobomol and M. Krüger, "Near-Eutectic Ternary Mo-Si-B Alloys - Microstructures and Creep Properties," JOM, vol. 68, pp. 2847-2853, 2016.

[17] Y. Yang, Y. A. Chang, L. Tan and Y. Du, "Experimental investigation and thermodynamic descriptions of the Mo-Si-Ti system," Materials Science and Engineering A, vol. 361, pp. 281293, 2003.

[18] S.-L. Chen, F. Zhang, F.-Y. Xie, S. Daniel, X.-Y. Yan, Y. A. Chang, R. Schmid-Fetzer and W. A. Oates, "Calculating phase diagrams using PANDAT and panengine," JOM, vol. 55, pp. 48-51, 2003.

[19] J. Nelson and D. Riley, "An experimental investigation of extrapolation methods in the derivation of accurate unit-cell dimensions of crystals," Proceedings of the Physical Society, vol. 57, p. 160, 
1945.

[20] D. S. Tsai, T. S. Chin, Hsu and M. P. S. E. \& Hung, "A Simple Method for the Determination of Lattice Parameters from Powder X-ray Diffraction Data," Materials Transactions JIM, vol. 30, pp. 474 - 479, 1989.

[21] I. Rosales and J. Schneibel, "Stoichiometry and mechanical properties of Mo3Si," Intermetallics, vol. 8, pp. 885-889, 2000.

[22] A. Gulec, X. Yu, M. Taylor, J. H. Perepezko and L. Marks, "Direct observation of incommensurate structure in Mo3Si," Acta Crystallographica Section A, vol. 72, pp. 660-666, 2016.

[23] S. Majumdar, B. Paul, P. K. Singh, J. Kishor and V. Kain, "Effect of Si content on microstructure, mechanical and oxidation properties," Intermetallics, vol. 100, pp. 126-135, 2018.

[24] Z. Tang, J. J. Williams, A. J. Thom and M. Akinc, "High temperature oxidation behavior of Ti5Si3-based intermetallics," Intermetallics, vol. 16, pp. 1118-1124, 2008.

[25] R. Mitra and V. V. Rama Rao, "Elevated-Temperature Oxidation Behavior of Titanium Silicide and Titanium Silicide-Based Alloy and Composite," Metallurgical and Materials Transactions A, vol. 29, pp. 1665-1675, 1998.

[26] A. Abba, A. Galerie and M. Caillet, "High-Temperature Oxidation of Titanium Silicide Coatings on Titanium," Oxidation of Metals, vol. 17, pp. 43-54, 1982.

[27] K. L. Luthra, "Stability of Protective Oxide Films on Ti-Base Alloys," Oxidation of Metals, vol. 36, pp. 475-490, 1991.

[28] M. Azim, D. Schliephake, C. Hochmuth, B. Gorr, H.-J. Christ, U. Glatzel and M. Heilmaier, "Creep Resistance and Oxidation Behavior of Novel Mo-Si-B-Ti Alloys," JOM, vol. 67, pp. $2621-2628,2015$. 
[29] K. Sadananda, C. R. Feng, R. Mitra and S. C. Deevi, "Creep and fatigue properties of high temperature silicides and their composites," Materials Science and Engineering A, vol. 261, pp. 223-238, 1999.

[30] R. Rosenkranz, G. Frommeyer and W. Smarsly, "Microstructures and properties of high melting point intermetallic Ti5Si3 and TiSi2 compounds," Materials Science and Engineering A, vol. 152, pp. 288-294, 1992.

[31] D. L. Anton and D. M. Shah, "High Temperature Properties of Refractory Intermetallics," Materials Research Society Symposia Proceedings, vol. 213, pp. 733-739, 1991.

[32] M. K. Meyer, M. J. Kramer and M. Akinc, "Compressive creep behavior of Mo5Si3 with the addition of boron," Intermetallics, vol. 4, pp. 273-281, 1996.

[33] G. Hasemann, I. Bogomol, D. Schliephake, P. I. Loboda and M. Krüger, "Microstructure and creep properties of a near-eutectic directionally solidified multiphase Mo-Si-B alloy," Intermetallics, vol. 48, pp. 28-33, 2014.

[34] P. Jain and K. S. Kumar, "Tensile creep of Mo-Si-B alloys," Acta Materialia, vol. 58 , pp. 21242142,2010 .

[35] A. P. Alur, N. Chollacoop and K. S. Kumar, "High-temperature compression behavior of Mo-SiB alloys," Acta Materialia, vol. 52, pp. 5571-5587, 2004.

[36] C. Hochmuth, D. Schliephake, R. Völkl, M. Heilmaier and U. Glatzel, "Influence of zirconium content on microstructure and creep properties of Mo-9Si-8B alloys," Intermetallics, vol. 48, pp. 3-9, 2014.

[37] J. H. Schneibel, "High temperature strength of Mo5Si3-Mo3Si-Mo5SiB2 molybdenum silicides," Intermetallics, vol. 11, pp. 625-632, 2003.

[38] P. Jéhanno, M. Heilmaier, H. Saage, M. Böning, H. Kestler, J. Freudenberger and S. Drawin, 
"Assessment of the high temperature deformation behavior of molybdenum silicide alloys,"

Materials Science and Engineering A, vol. 463, pp. 216-223, 2007.

[39] K. S. Kumar and A. P. Alur, "Deformation behavior of a two-phase Mo-Si-B alloy," Intermetallics, vol. 15, pp. 687-693, 2007.

[40] P. Jéhanno, M. Heilmaier, H. Saage, H. Heyse, M. Böning, H. Kestler and J. H. Schneibel, "Superplasticity of a multiphase refractory Mo-Si-B alloy," Scripta Materialia, vol. 55, pp. 525$528,2006$.

[41] J. W. Pugh, "The tensile properties of molybdenum at elevated temperatures," Trans. ASM, vol. 47, p. $984,1955$.

[42] H. J. Frost and M. F. Ashby, Deformation mechanism maps: the plasticity and creep of metals and ceramics, Oxford, UK: Pergamon Press, 1982.

\section{Supplementary material}

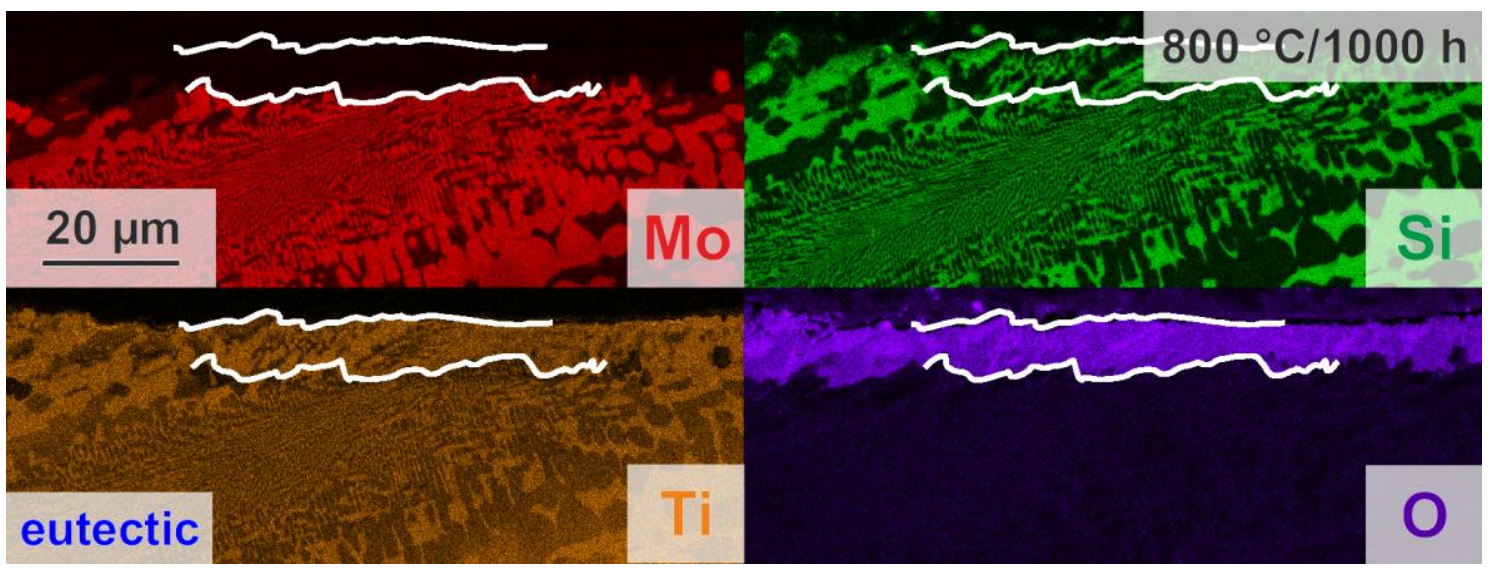

Figure 14: Supplementary SEM-EDX maps of the scale cross sections subsequent to $1000 \mathrm{~h}$ of cyclic oxidation of the eutectic alloy at $800{ }^{\circ} \mathrm{C}$. White lines indicate the substrate/scale interface and the surface of the scale, respectively. 


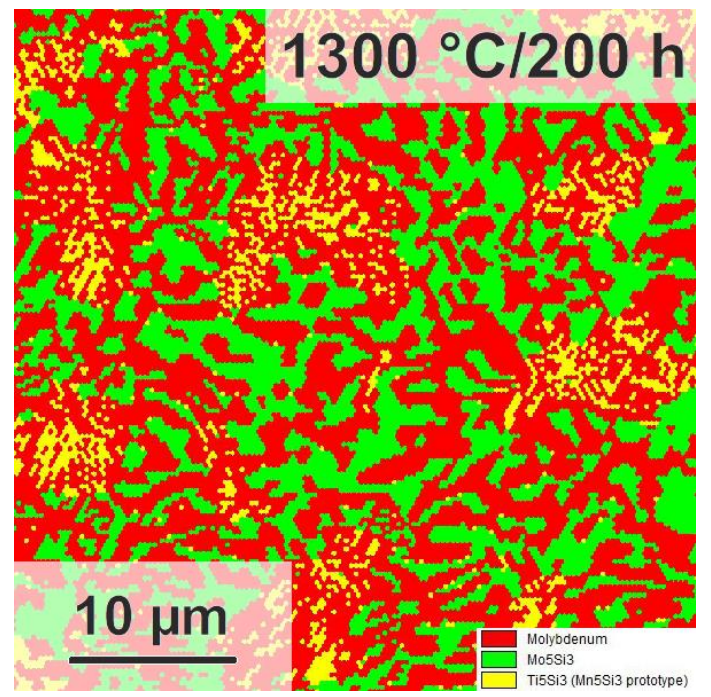

Figure 15: Supplementary SEM-EBSD map of the eutectoid alloy subsequent to entire decomposition at $1300{ }^{\circ} \mathrm{C}$ for $200 \mathrm{~h}$. 